\title{
Crustal Relaxing - a New Seismogenesis Phenomenon associated with Seismic Trigger on a global scale
}

\author{
Daniele Cataldi $^{1-2}$, Valentino Straser ${ }^{3}$, Gabriele Cataldi ${ }^{4}$
}

\author{
1) Radio Emissions Project - Lariano, Rome, Italy; 2) Permanent Foundation G. Giuliani - \\ L'Aquila, Italy; 3) Department of Science, Environment Energy, UPKL Brussel, Belgium; 4) \\ Radio Emissions Project - Albano Laziale, Rome, Italy. \\ daniele77c@hotmail.it ${ }^{1-2}$; valentino.straser@gmail.com ${ }^{3}$; Itpaobserverproject@gmail.com ${ }^{4}$
}

DOI: 10.26821/IJSRC.9.7.2021.9711

\begin{abstract}
In this study a new seismogenetic mechanism is proposed, based on the analysis of magnitude earthquakes exceeding 6, which occurred on a global scale, with the epicenters located in the area of the terrestrial terminator. The study, begun in 2011, is based on over a thousand data on potentially destructive earthquake, including those associated with tides. The terminator band separates the shadow area from that illuminated by the Sun. In this research it is assumed that at the transition band the gravitational forces of the sun
\end{abstract}

\section{1 - Premise}

The fundamental geofisic parameters of the earth are a result of the global composition, the distribution of the masses and the dynamics of the planet. The main levels of the interior of the Earth have distinct chemical and seismic properties.

The information available, largely come from indirect methods such as the study of the speed variations of seismic waves, the mass budgets of the planet, geochemical speculations on global composition, variations in gravimetric and magnetic fields [8].

Its composition is very heterogeneous, the complex mechanisms of the tenderosphere and the cloak, subjected to the gravitational attraction of the celestial bodies, tend to arouse the earth's surface, with the effect of sliding of the continents, this phenomenon is known as "mareal push" Of the magma, determined by the gravitational interaction from the stars, such as the Sun and the Moon, and the Moon, bribes to the earth's surface. This area, named by the authors: "Crustal Relaxing", is subject to stress induced by the two celestial bodies that can evolve into seismic events. The partial outcome of this research, still in progress, confirms the potential relationship between the occurrence of strong earthquakes with the stress induced by the gravitational action exercised by the Sun and the Moon.

Keywords: Earthquake forecast, Astronomical interacton, Geophisics, Seismic trigger.

which being the nearest celestial bodies and larger, compared to the distance from the Earth, are able to interact more than the other planetary bodies scattered in the solar system.

The same tectonic equator follows the trajectory of the Moon.The astronomical forces act on the lithosphere, as well as on the portions of the seas and oceans [7], although with less intensity, being the rock and the much more dense and viscous magma of the water that covers the earth's surface.

These motions are essential for the displacement of the plates and for the motions that determine the drift of the continents, which move slowly westwards [1], In this regard, it should be considered the drag or seagaring (Tidal Drag) which is the push towards the west due to the delay of the seaglement with the gravitational alignment Earth-Moon and Earth-Sun (seeFig. 1) [8]. 
Recently it was proposed that the terrestrial rotation, coupled to the convection of the mantle and the non-linear rheology of the asthenosphere, can be considered a primary cause of the tectonics of the plates both in terms of energy and of movement directions

$[8]$.

\section{2 - CORRELATION DATA}

To begin to consider this interaction, in less complex terms, we must take into account the extended vision of the terrestrial surface, which as we know is illuminated by the Sun, and illuminates about half.

This illuminated area is divided by the area in shadow from a hypothetical circumference (area), thick several hundred kilometers, called "terminator".

The dilimeting terminator, therefore, the area of the terrestrial surface illuminated by the sunlight and that covered by the earth shadow and indicates, in a hypothetical way, the area where the lunar and solar gravitational attraction are arranged parallel to the terrestrial surface in a "ring road to the earth's surface".

The terminator shows the gradual transition to the darkness that manifests itself at the twilight on the surface of the earth, compared to the illuminated part.

The orientation of the terminator between the north and south hemisphere depends on the season, being the planetary sphere crushed to the poles and elongated to the equator (precisely due to such strength), the interaction on the terrestrial surface varies according to the latitude.

During the equinoxes, for example, there is no inclination of the Earth compared to the Sun so the terminator is parallel to the earth axis.

These mechanisms, for many years have been underestimated by science, but today these phenomena can no longer be not considered, precisely because the earth is a system in which different physical forces interact and each of these determines an effect on his body, which cannot Certainly be underestimated.

The earth's rotation joins the forces that act on the magmatic tide and this generates, on the surface on the most superficial layer and less often than the terrestrial crust (lithosphere), very intense effects, due to the static nature of the structures that the layer is characterized. We are at a point where the rock is solid and therefore no longer melted or viscose, therefore the interaction on that layer, determines often irreversible changes.

We know that the asthenosphere, placed below the lithosphere, is the area with a lower viscosity of the cloak also due to the presence of fluids such as $\mathrm{H}_{2} \mathrm{O}$ and $\mathrm{CO}_{2}$, although it can reach a temperature of $1400^{\circ} \mathrm{C}$ is not in the liquid state Because the pressure maintains the rock in solid state.

The rocks of the asthenosphere are therefore close to the fusion point but still have a plastic behavior. In the astrosphere, convective motions caused by heat coming from the core tend to move the overlying lithosphere.

The asthenosphere then exercises strong pressure on the lithosphere that being fragile tends locally to shattering and branched [19]. This therefore generates instability, caused by repeated sea thrusts, right on overlying lithosphere (Fig. 1). In this context, gravitational forces determine a strong boosted to weak structures such as those present in fault surfaces. 

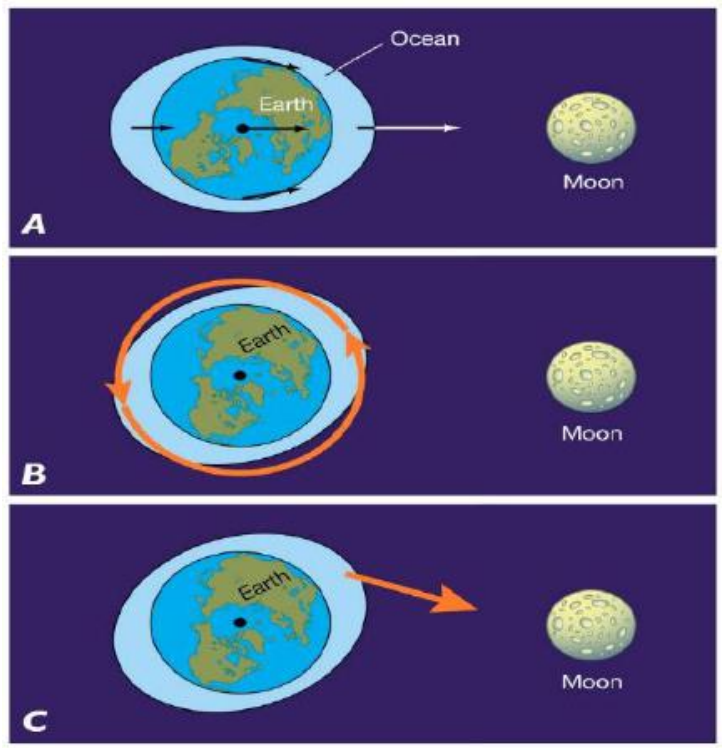

Fig.1 - (A) The Moon's gravity raises ocean tides on the Earth. (B) The rotation of the Earth pulls the tides out of alignment with the Moon. (C) The Moon tries to pull the tides back into a line, slowing the rotation of the Earth. As for the masses of water, the Moon and the Sun, they are able to make a direct effect on the liquid magma whose planet Earth is constituted. The influence on this mass of liquid rock, determines influences on the very drift of the continents. Credits: writescience.wordpress.com.

\section{1 - The NeW Trigger Phenomena}

In 2011, following the study of some earthquakes, the researchers engaged in this study had the opportunity to observe what seemed an innovative sismogenesis mechanism, never highlighted before. A certain percentage of earthquakes, both small and strong intensity, seemed to take place near the terrestrial terminator.

Not only that, the observations showed that a certain percentage of such earthquakes occurred in line with the position of the Sun (Solar Zenith) and the Moon (Lunar Zenith), especially when these celestial bodies were at their highest elevation, compared to the geographical area in which these ses were presented.

The researchers, therefore, have begun to advance different working hypotheses, to try to understand why a certain number of earthquakes seemed to occur in the aforementioned conditions.

Everything seems to be linked to the sphericality of the Earth and the gravitational interaction that the Sun and the Moon determine on the earth's surface, under certain conditions.

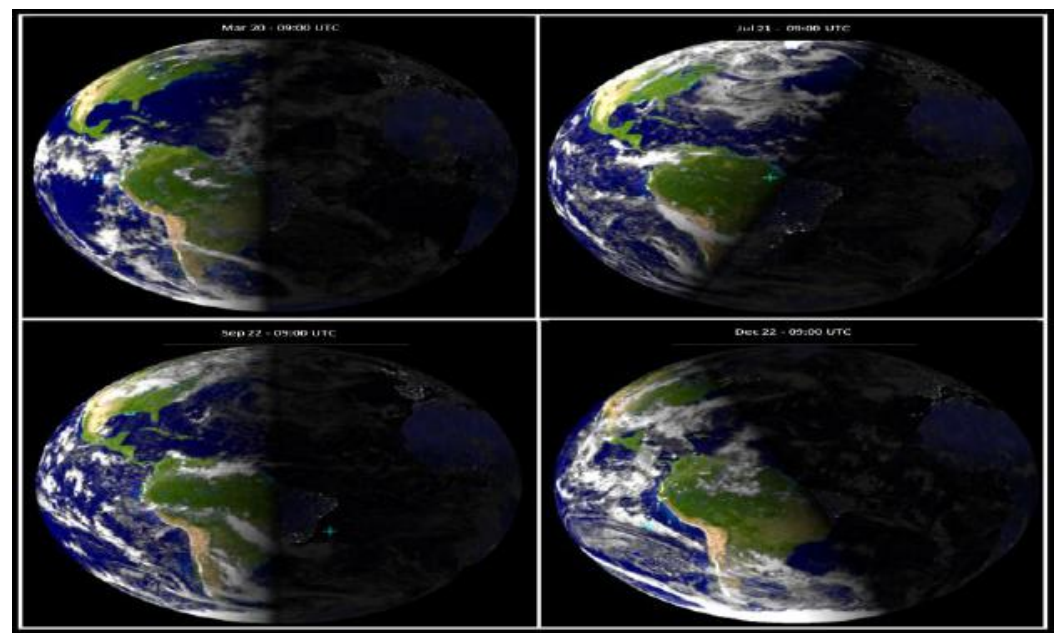

Fig.2 - Terrestrial terminator, and its variation of inclination with respect to different periods of the year. Credits: public domain. 
Volume 9 Issue 7 July 2021

This phenomenon was defined by the team of the researchers as: "Crustal Relaxing", or a phenomenon generated by the Sun and the Moon, compared to their orbital position. From a gravitational point of view the sun determines a continuous interaction on the earth's surface, and with it even the Moon. This mechanism seems to be related to the occurrence of a certain number of earthquakes, especially when the areas with greater tectonic stress seem close to the terminator and proximity of the solar or lunar zenith.
This new phenomenon had already been identified by the Radio Emissions Project, in 2011, following the strong earthquakes that at that time they had affected the peaceful area [2] (Fig. 5, 6, 7). The correlation with the position of the seismic epicenter and the proximity to the terrestrial terminator was made possible thanks to the use of "Orbitron", a software used for satellite ephemeris, used by the radio emissions project for viewing the terrestrial map and for the identification of the illuminated area and that in the shadow, as well as the position of the sun and the Moon[3].

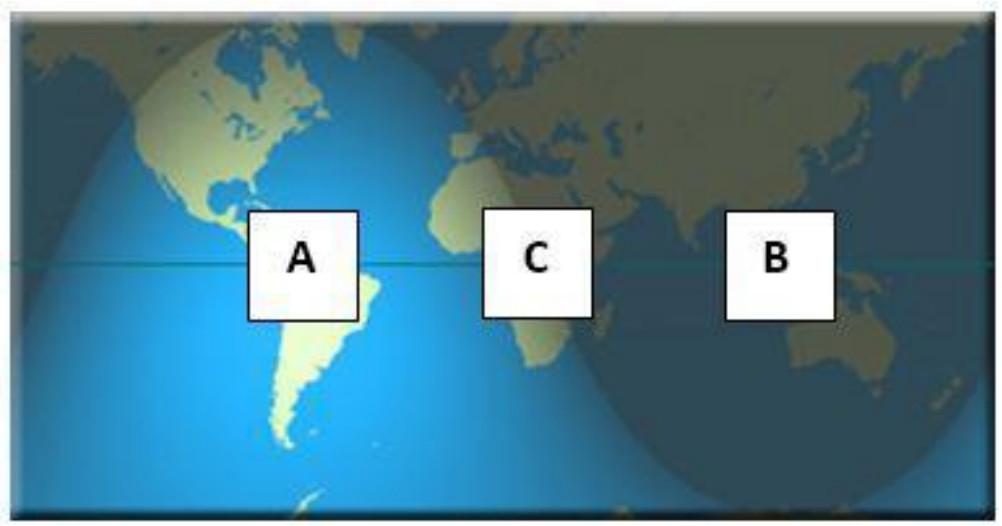

Fig.3 - Earth map in which the various elements are observed that identify the terrestrial terminator $(C)$, thanks to the area lit by the sun (A) and the one in shadow (B). These elements seem to be important in a context of seismogenesis, in which the terrestrial surface is expanded due to the gravitational interaction between sun and earth. Credits: public domain.

According to data, the "lithosphheric distension" acts as follows (Scheme 1):

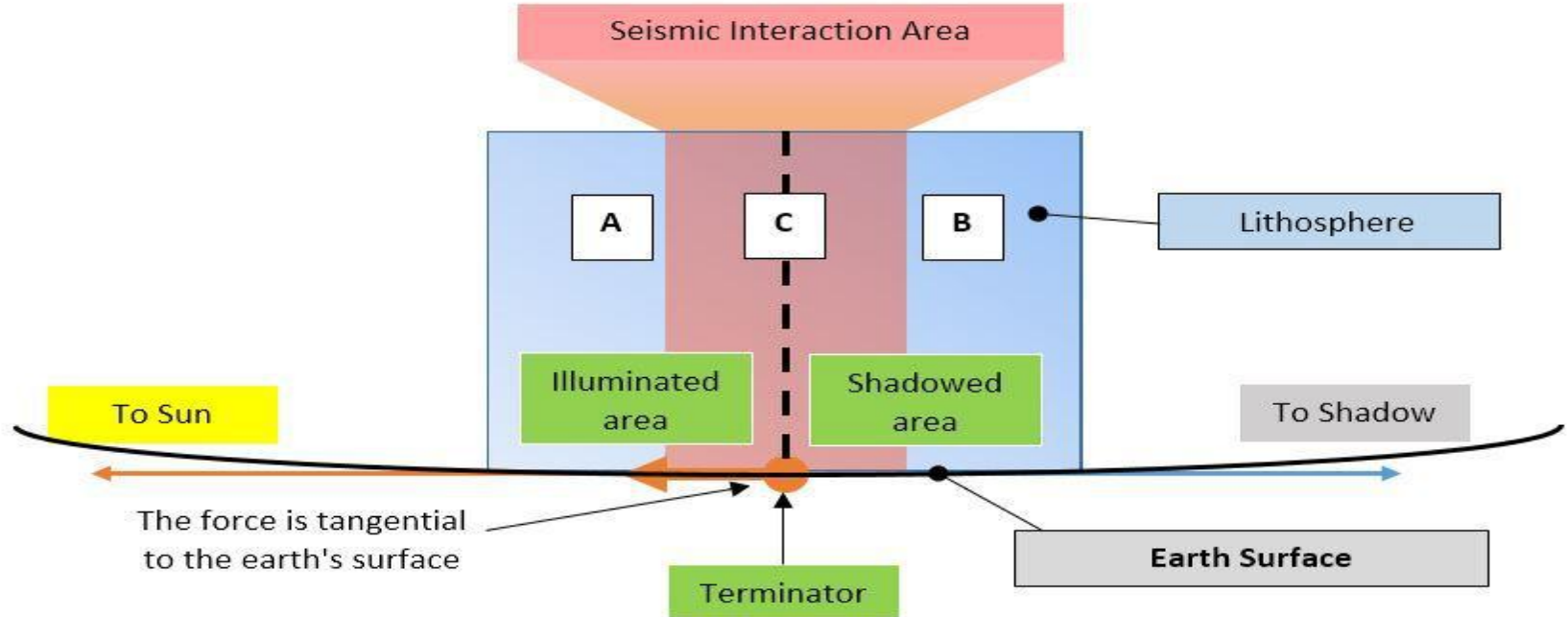

Scheme 1 - Forces at stake, in relation to the phenomenon of "Crustal Relaxing", discovered by the Radio Emissions Project, and associated with the context of seismic trigger on a global scale. Credits: Radio Emissions Project.

The area of "seismic interaction" is the one in by the sun, are important. To date, there is no possibility to measure these forces, even if from a physical point of view, science already explains such mechanisms [1]. which the earthquakes seem to take place and in which the effects of "stretching" of the lithosphere 
The traction determined by the gravitational interaction, tends to "stretch" the terrestrial surface (due to the forces that are tangentials here to the earth's surface), going to interact, on a certain area of the earth's surface, on the distances that separate the limits of the faults, especially if these are long and extensive. Going to interact, on the earth's surface (which has a certain elasticity), it is obvious

that this interaction involves action, direct to the faults and the energy contained in them, going to interact directly on the seismogenesis.

The terrestrial terminator is defined as the set of points on a moon or planet where the rays that make up the solar radiation are tangent to the surface. The line separates portions of the land where light is present from those in which there is darkness [4]. The lines of force of gravitational attraction, act on the terminator in a ring road, such as to tract the earth's surface, and iron it, inducing the mechanisms already described.

If we calculate that the line of the terminator can move at a speed of $1.669 \mathrm{~km} / \mathrm{h}$ (considering the equatorial circumference of $40.075 \mathrm{~km}$ ) [5], We can certainly understand what kind of force is able to interact on the lithosphere in the " $\mathrm{C}$ " position.

From a warning point of view, even the "A" and "B" positions seem to have their relationship with certain earthquakes, when the position of the sun is accident with a high angle, and perpendicular to the position of Aro, respect At the earth's surface. At this point, the force acts by raising the lithosphere, and therefore acting not by traction, but for real lifting, triggering earthquakes, due to the effect of such interaction.

\section{2 - The NEW IDENTIFIED PhenOMENON}

In this new seismogenetic process, the researchers highlighted as earthquakes, they appear near particular gravitational processes, determined by the sun and the Moon. These processes are thus schematized:

I. TERMINATOR - Earthquakes that occurred near the terrestrial terminator.

II. LUNAR ZENITH - Earthquakes occurred to the axial proximity of the Moon, ie the
The Magma's sea interaction, content in the cloak and in the astrosphere is able to raise the earth's surface, in the area where the Moon is located. Both the Sun and the Moon determine what is known as "equatorial swelling", determined by the attraction of the sun and the Moon on the equator [6].

The combination of the two phenomena, astronomical and convective, would mean that the lithosphere is in a condition of permanent stress, where the moon and the sun slow down the Earth and the internal convection tends instead to accelerate it, even though the budget is negative, Since the Earth slows its rotation of about 1.8 milliseconds to the century.Astronomical drag is therefore not only responsible for the drift towards the west of the lithosphere, but also of the preferential direction of the movements of the plates that tend to dispose along a dominant flow, of sinusoidal shape, but not too far from the geometry of a maximum circle.

This flow tends to dispose with a lower angle of $30^{\circ}$ than the equator, very close to the ecliptic plane plus the top of the lunar revolution (about $28^{\circ}$ ). The tidal forces therefore seem to have a fundamental influence on the terrestrial dynamics, but they still have to be fully understood, although they are already known from the Hellenistic Age [8].

It is therefore understandable, according to such knowledge, that the phenomenon of "crustal relaxing" is not only a hypothesible phenomenon, but completely explained by the laws that regulate kinetics and terrestrial dynamics.

point where, prospectively the position of the Moon coincides with a certain point of the earth's surface.

III. SOLAR ZENITH - earthquakes occurred to the axial proximity of the Sun, or the point where, perspective the position of the Sun, coincides with a certain point of the earth's surface. 


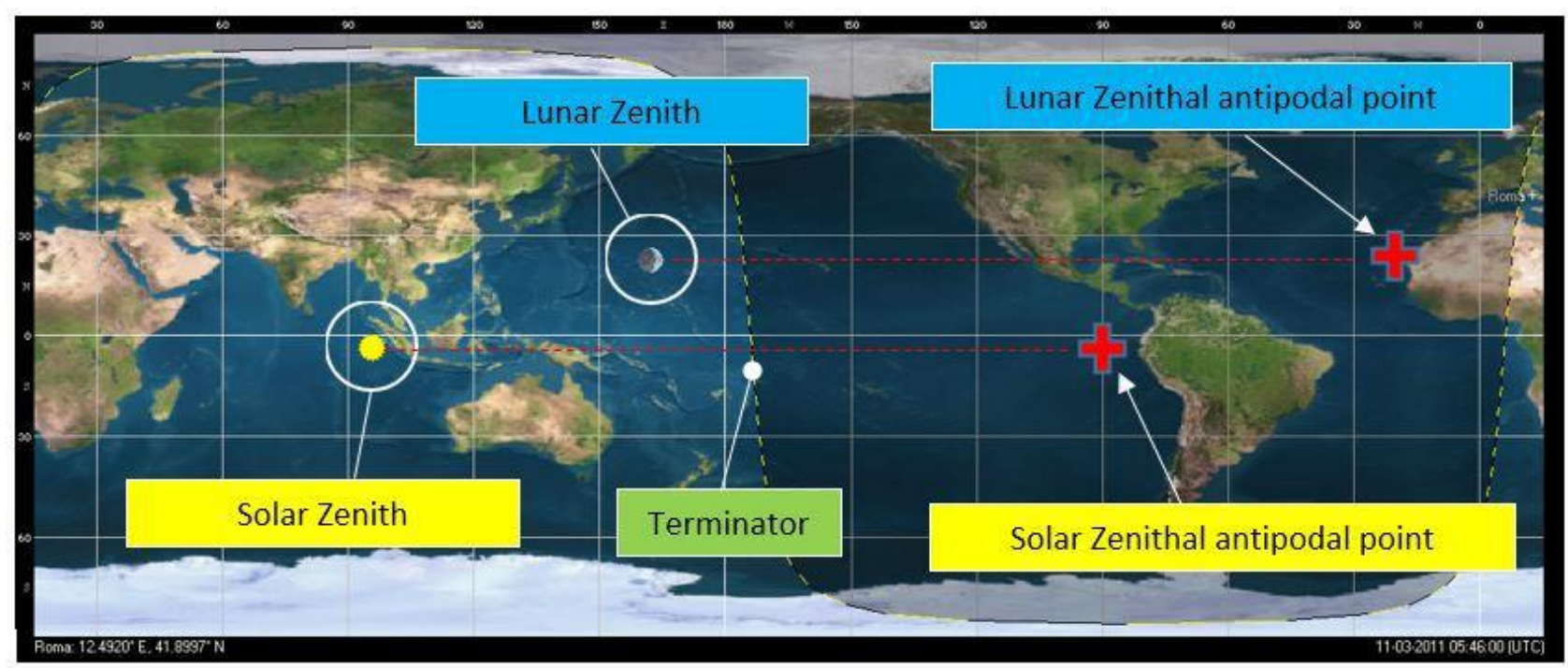

Fig.4 - Geographical diagram in which the various types of competing phenomena are observed in the seismic trigger mechanism, due to the "lithosphheric relaxation".Credits: Radio Emissions Project.

These phenomena, they affect more if close together. For example, a greater probability of trigger has shown when the Solar Zenith and Lunar Zenith are close to each other, in a restricted geographical area, or when one of those Zenith is in the vicinity of the terrestrial terminator. This fact can be explained with greater gravitational influence at the level of the lithosphere and the magma of the cloak, compared to the other points of the earth's surface. Also considered for example the "antipodal point" of Solar Zenith, and Lunar Zenith, which seems to have more influence than the other areas of the earth's surface. In this case, in fact, the gravitational interaction permeates perpendicularly the entire planetary body, also influencing the antipodal point.

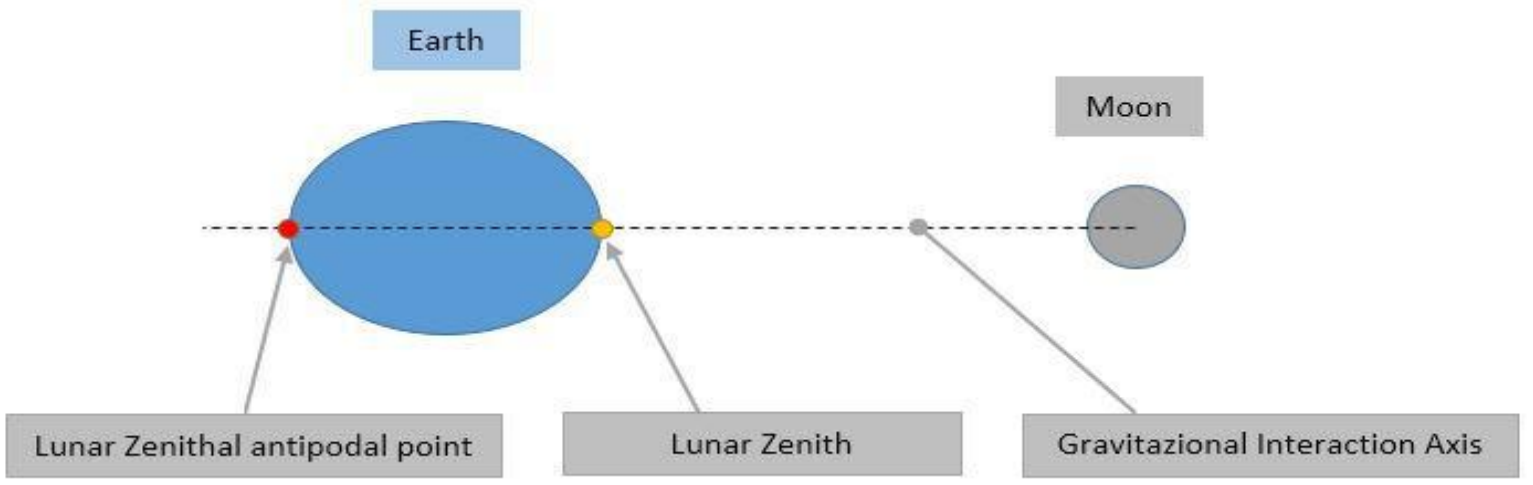

Scheme 2 - The axis of gravitational interaction, hypothesized in this study relates to the position of the Moon or Sun with its respective Zenith Point and Antipodal Point. Areas in which, on the earth's surface, seem seismic triggers seem more likely. It is hypothesized that these points of interaction can also be identified by observing the interaction with the other celestial bodies scattered in the solar system (planets). In this context, the evidence that different earthquakes occurred in these points, or in their restricted vicinity, suggests how there is a direct correlation between gravitational forces and the energy accumulated at the level of faults, subject to greater tectonic stress. Credits: Radio Emissions Project.

It is compliant that even the moon generates its "gravitational terminator" on the earth's surface, even if this was not, up to date, still hypothesized at the scientific level. It is shared by the researchers engaged in this study, that there is a well-specific area, generated by the gravitational interaction of the celestial bodies, and distributed on the terrestrial surface facing the Moon or front-Sun (and more generally than the position of the planets of the solar system), within which the possibility of seismic trigger is increased, for the mechanisms already described. 
Volume 9 Issue 7 July 2021

\section{3 - SEISMIC DATA}

The seismic data, considered since March 2011, immediately showed that there was an interaction, albeit apparent, with the dynamics of terrestrial kinetics and with the gravitational interaction of the celestial bodies close to the planet. The data considered in this study depart from 2011.

Mw 9.0 - March 11, 2011 - UTC Time: 05:46 - Japan - GPS: Latitude: 38.297 - Longitude: 142.372.

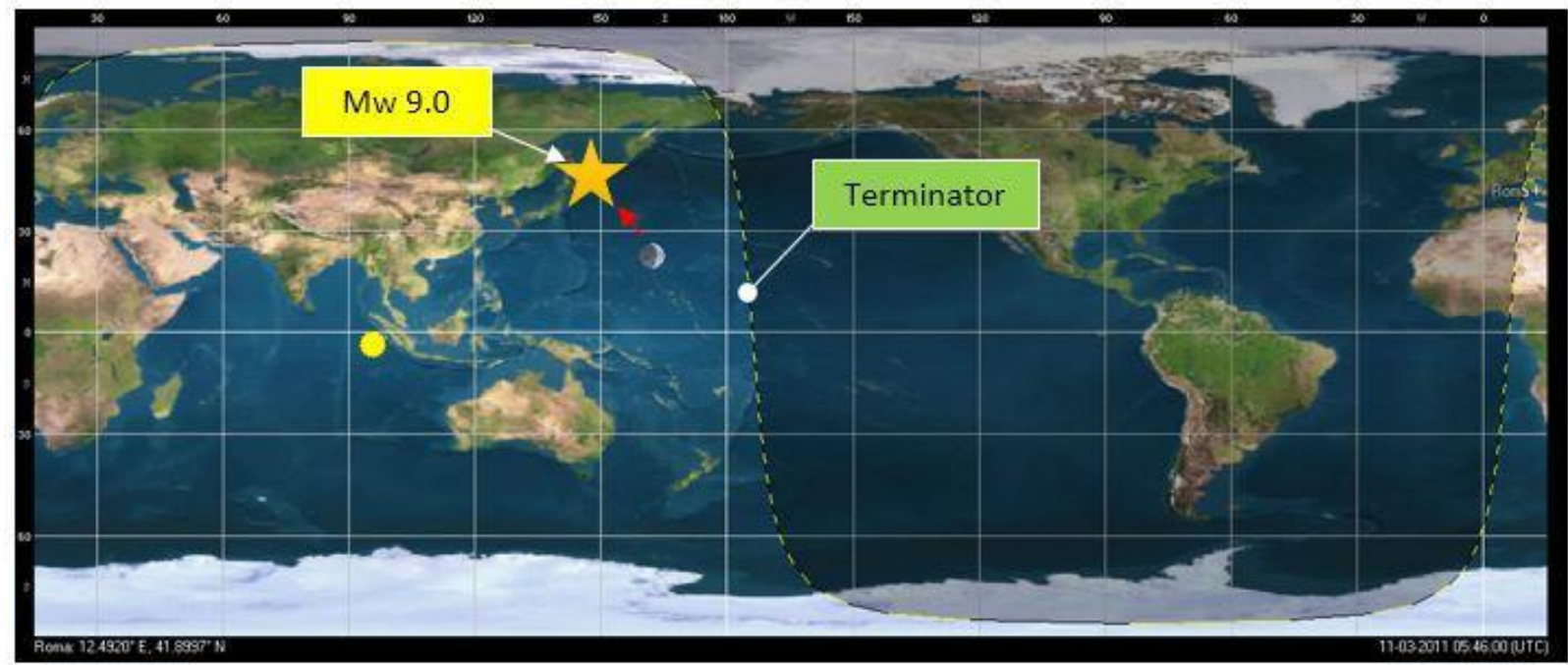

Fig.5 - Earthquake Mw 9.0 - of 11 March 2011 - Japan. The earthquake, in this case occurred in close correspondence with the lunar Zenith and a short distance from the terrestrial terminator. Credits: Radio Emissions Project, USGS.

Mw 7.9 - March 11, 2011 - UTC Time: 06:15 - Japan - GPS: Latitude: 36.281 - Longitude: 141.111.

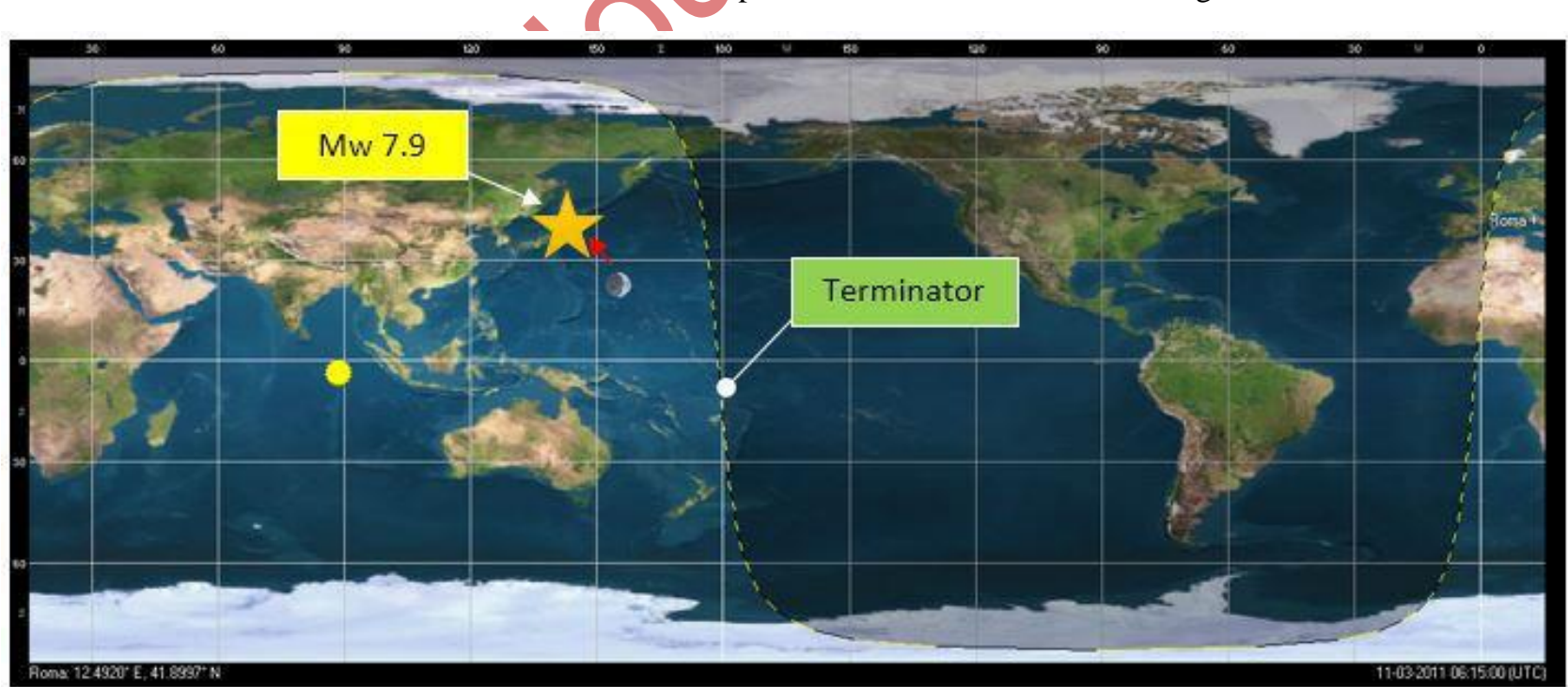

Fig.6 - Earthquake Mw 7.9 - of 11 March 2011 - Japan. The earthquake, in this case occurred in close correspondence with the lunar Zenith and a short distance from the terrestrial terminator. Credits: Radio Emissions Project, USGS. 
Mw 7.1 - March 11, 2011 - UTC Time: 06:25 - Japan - GPS: Latitude: 38.106 - Longitude: 144.553.

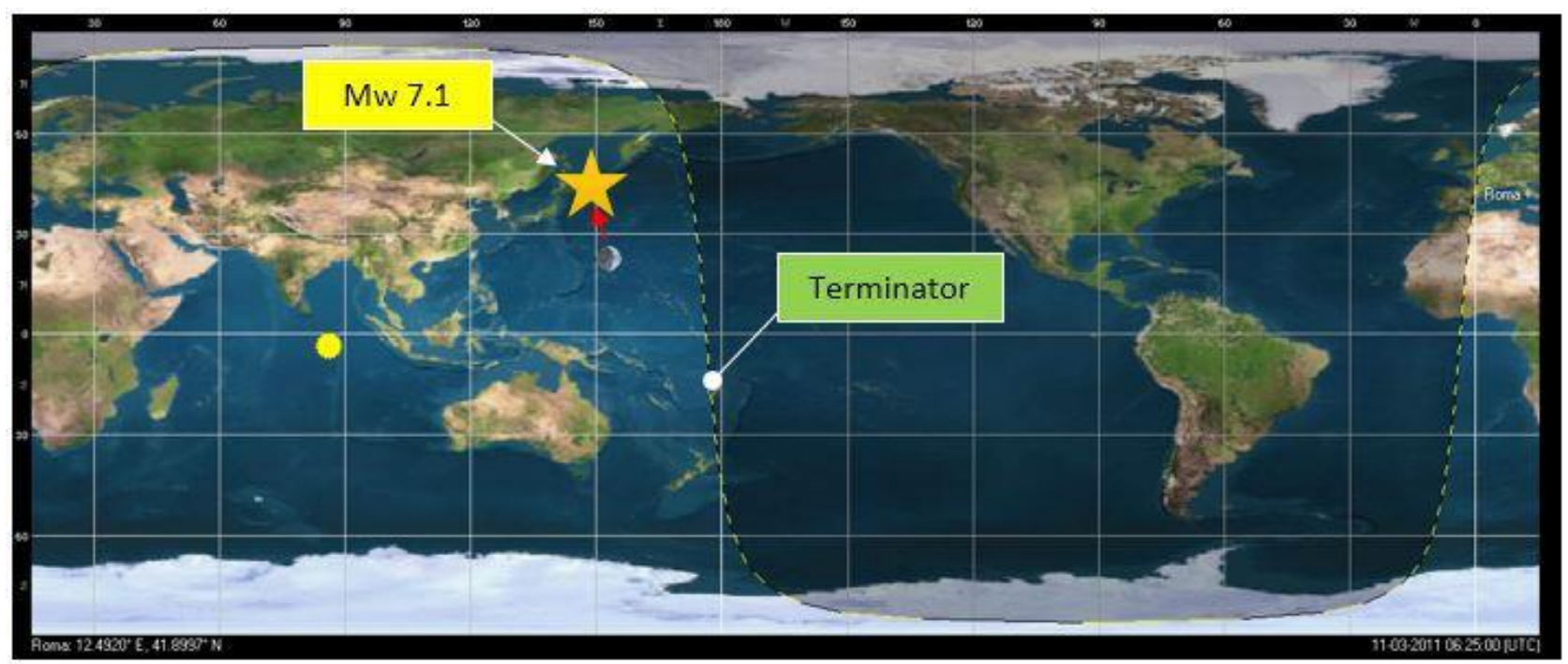

Fig.7 - Earthquake Mw 7.1 - of 11 March 2011 - Japan. The earthquake, in this case occurred in close correspondence with the lunar Zenith and a short distance from the terrestrial terminator. Credits: Radio Emissions Project, USGS.

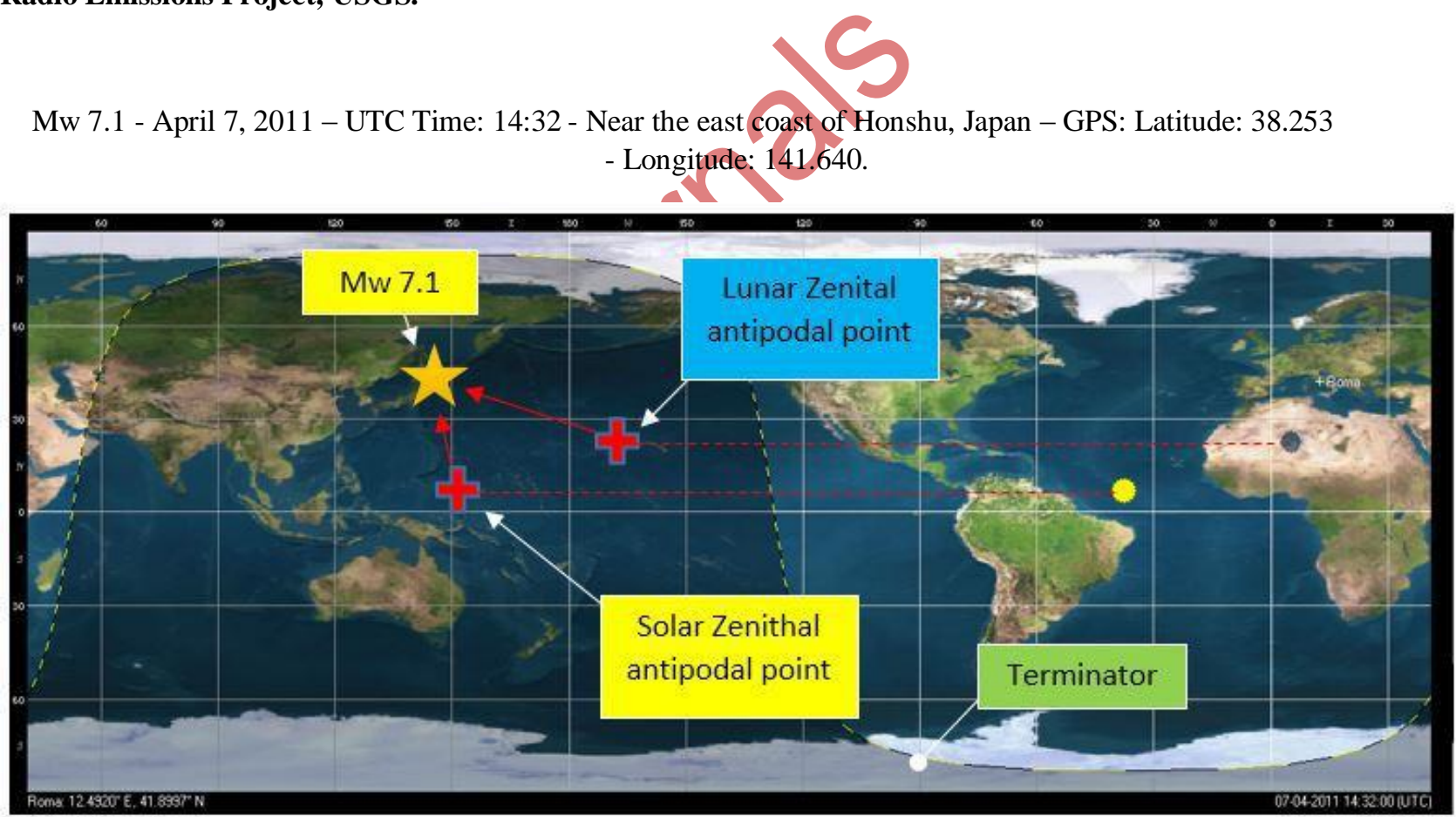

Fig.8 - Earthquake Mw 7.1 - of 7 April 2011 - Japan. Earthquake occurred near the lunar and solar zenital antipodal points and very close to the terrestrial terminator. The influence of such astronomical depth points, in this case, is very evident. Credits: Radio Emissions Project, USGS. 
Volume 9 Issue 7 July 2021

Mw 7.1 - April 7, 2011 - UTC Time: 08:16 - Near the east coast of Honshu, Japan - GPS: Longitude: 37.007 Latitude: 140.477.

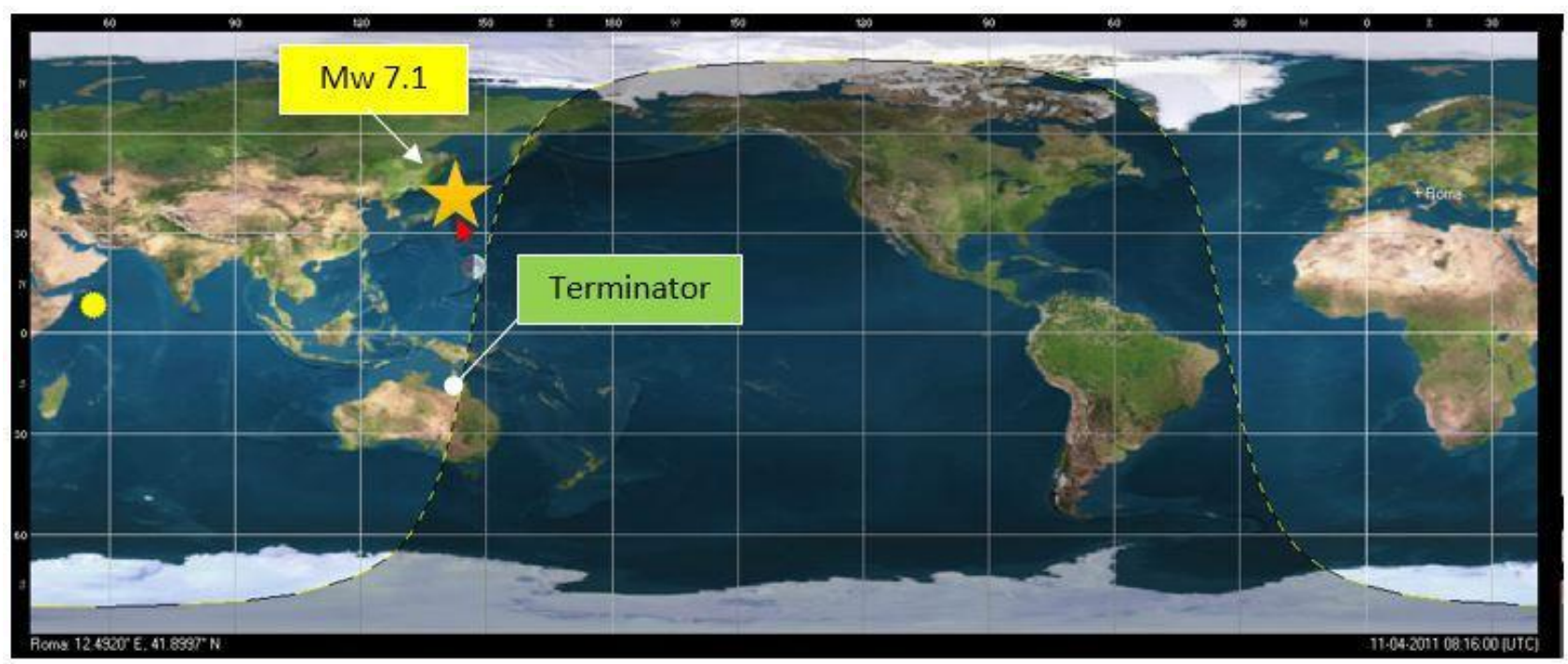

Fig.9 - Earthquake Mw 7.1 - of 11 April 2011 - Japan. The earthquake, in this case occurred in close correspondence with the lunar Zenith and a short distance from the terrestrial terminator. Credits: Radio Emissions Project, USGS.

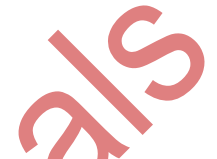

Mw 7.6 - July 6, 2011 - UTC Time: 19:03 - Kermadec ISlands region, New Zealand - GPS: Latitude: -29.312 Longitude: -176.204

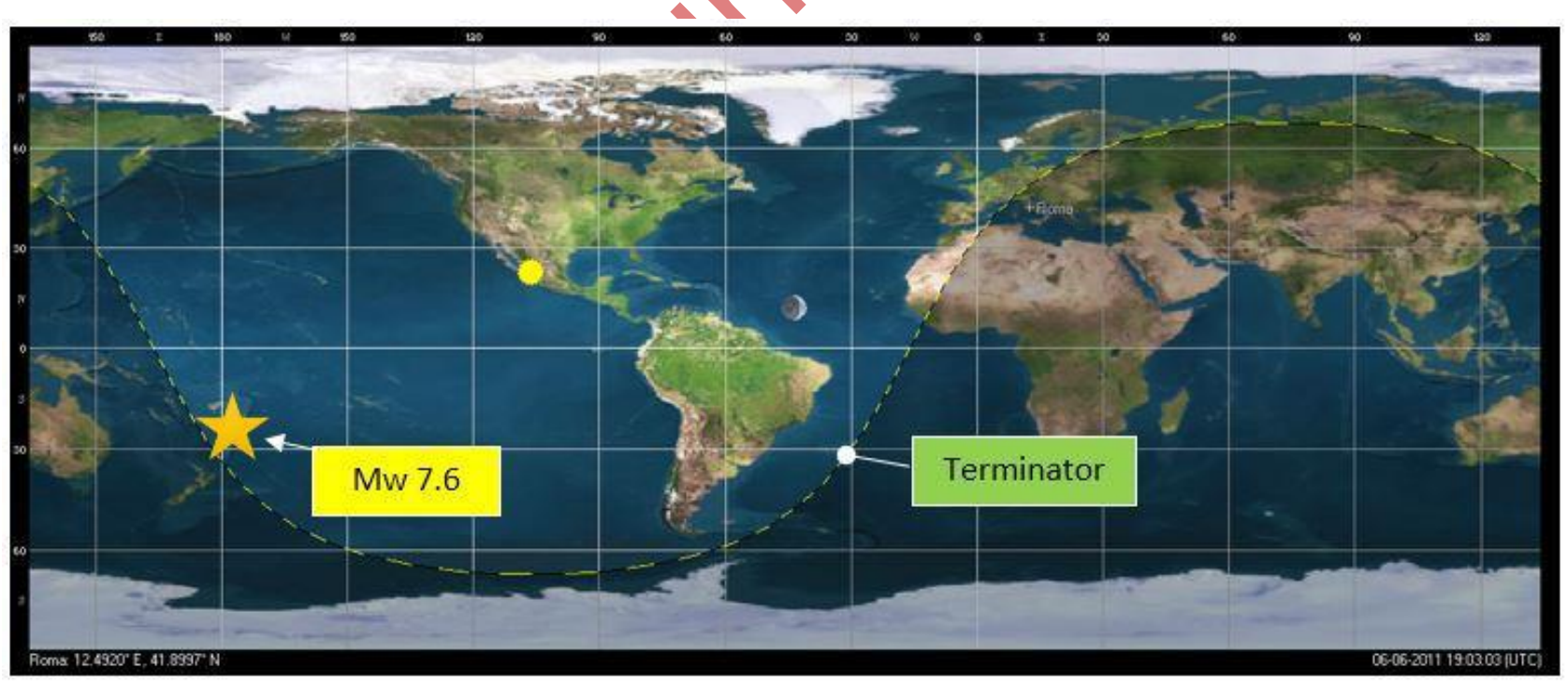

Fig.10 - Earthquake Mw 7.6 - of 6 july 2011 - Kermadec Islands. The earthquake, in this case occurred in close correspondence of the terrestrial terminator. Credits: Radio Emissions Project, USGS.

Mw 7.1 - August 20, 2011 - UTC Time: 16:55 - Vanuatu - GPS: Latitude: -18.260 - Longitude: 168.069: 


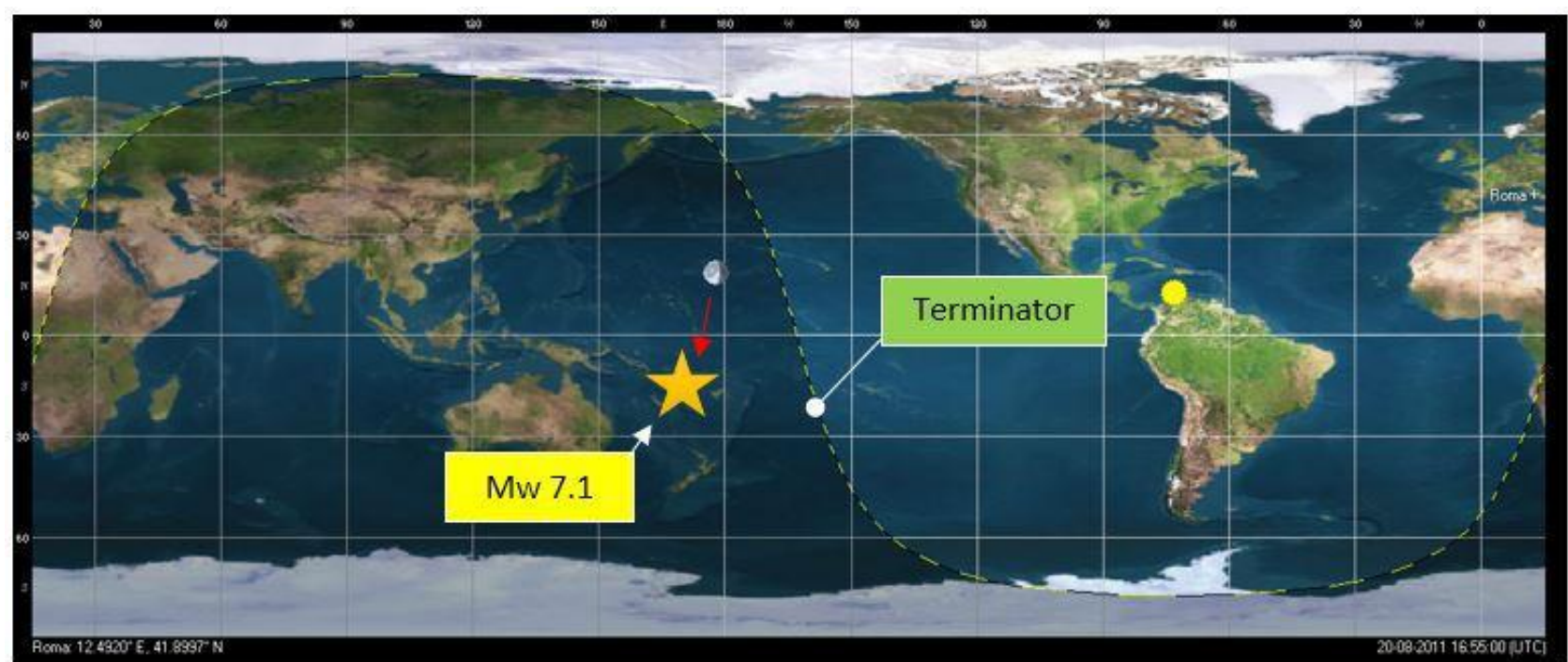

Fig.11 - Earthquake Mw 7.1 - of 20 August 2011 - Vanuatu. The earthquake, in this case occurred near the terrestrial terminator and with the position of the lunar zenith. Credits: Radio Emissions Project, USGS.

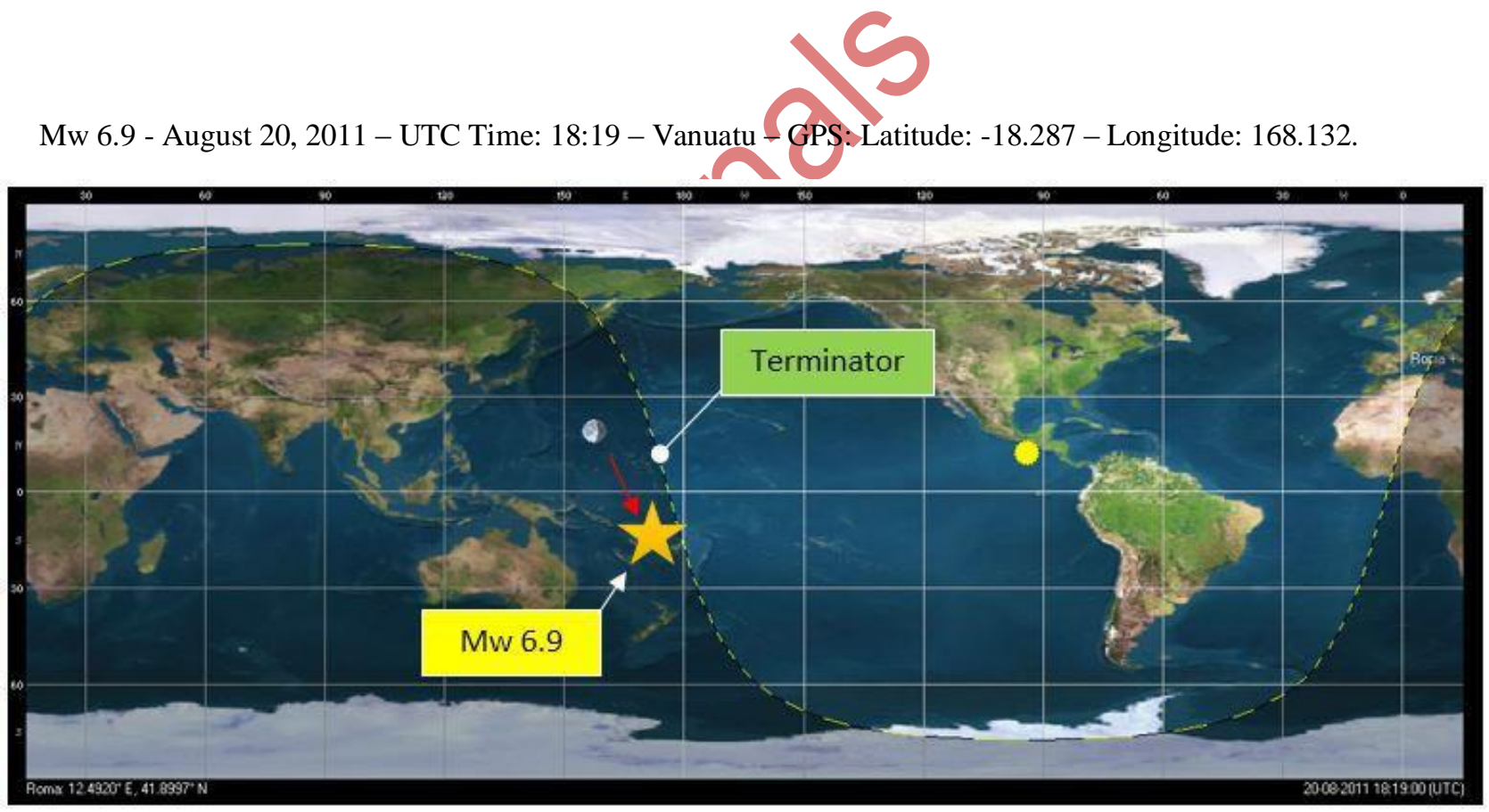

Fig.12 - Earthquake Mw 6.9 - of 20 August 2011 - Vanuatu. The earthquake, in this case occurred near the terrestrial terminator and with the position of the lunar zenith. Credits: Radio Emissions Project, USGS. 


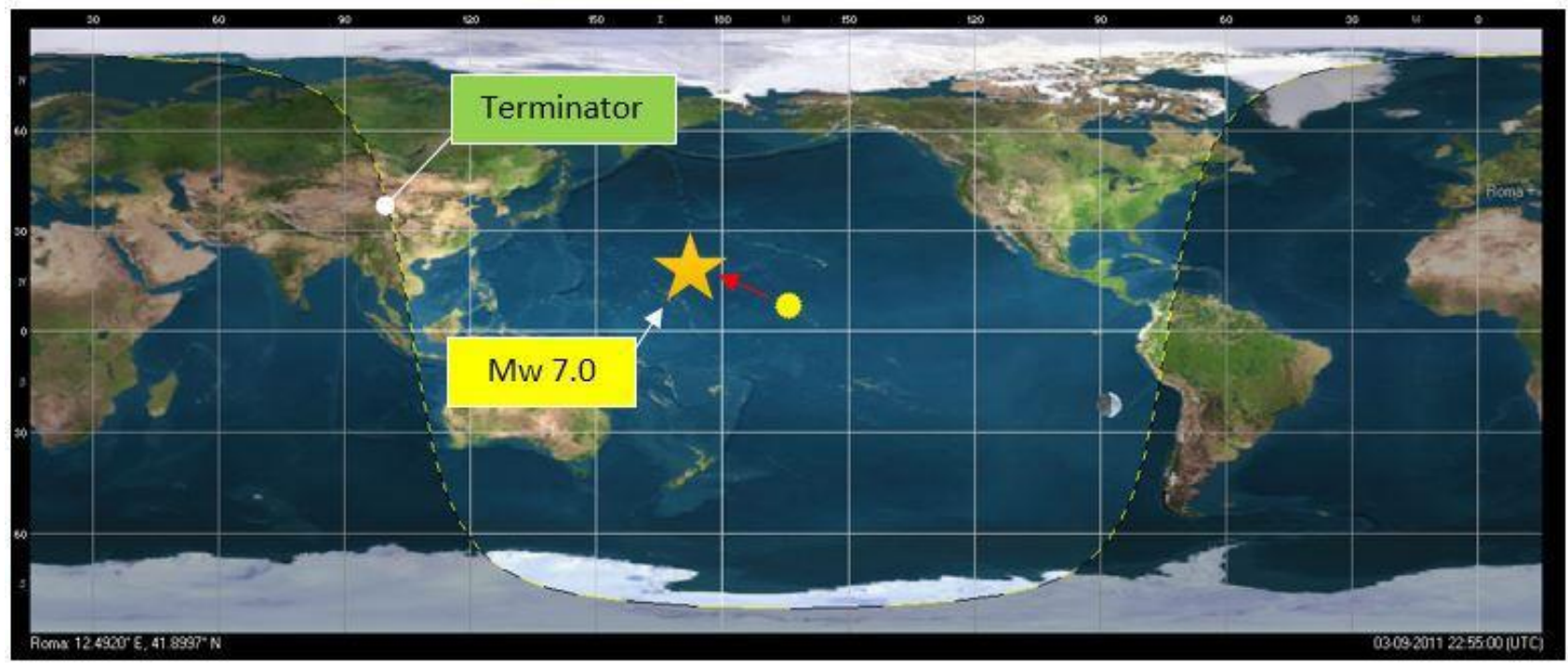

Fig.13 - Earthquake Mw 7.0 - of 3 September 2011 - Vanuatu. Earthquake did not take place on the terminator, but near the solar zenith point. Credits: Radio Emissions Project, USGS.

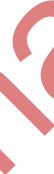

Mw 7.3 - September 15, 2011 - UTC Time: 19:31 - Fiji region - GPS: Latitude -21.559 Longitude: -179.369 Terrestrial terminator occurred at the specific UTC time:

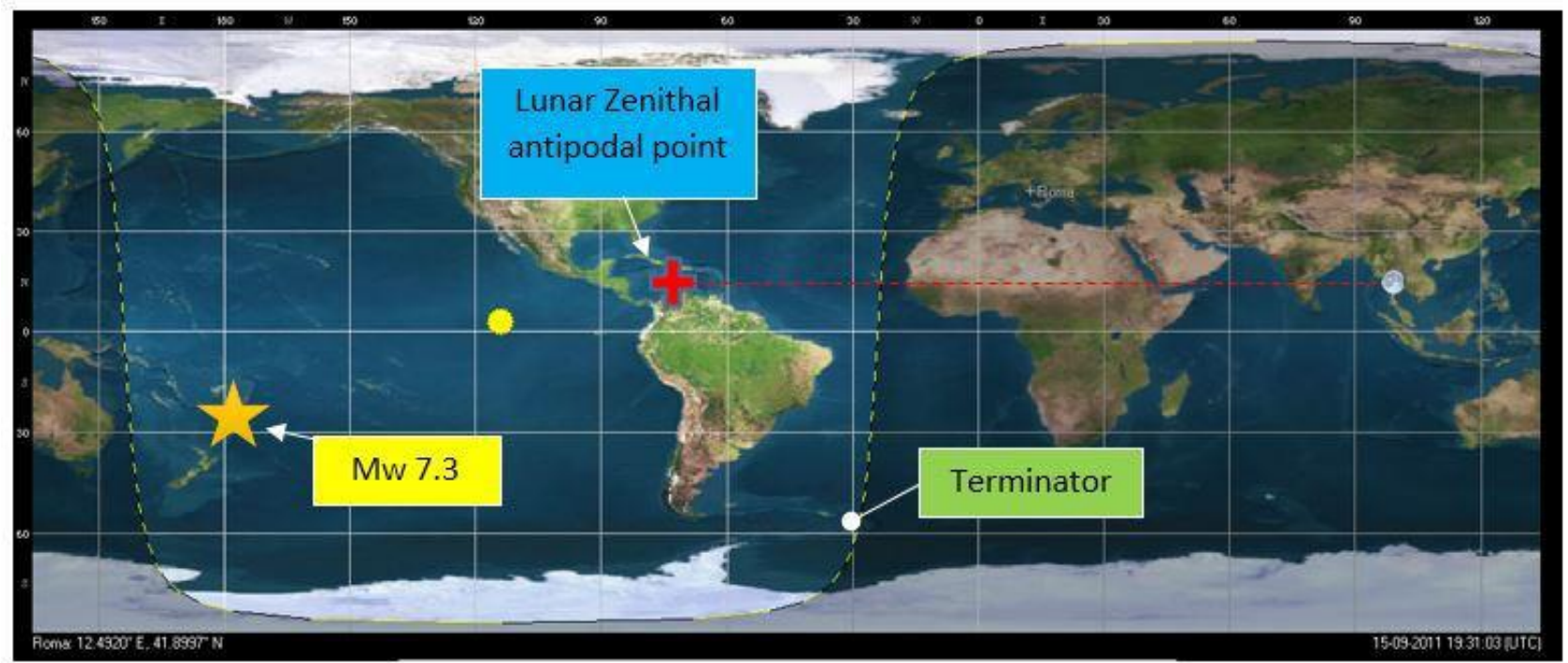

Fig.14 - Earthquake Mw 7.3 - of 15 September 2011 -Fiji region. In this case is the position of the Sun and the Moon, which are opposed to the earth's surface, have gravitationally influenced the traction of the earth's surface, pushing from two opposite points, as happens when a rubber band tends. Credits: Radio Emissions Project, USGS. 
Mw 6.9 - September 18, 2011 - UTC Time: 12:40 - India-Nepal border region - GPS Latitude: 27.723 Longitude: 88.064 .

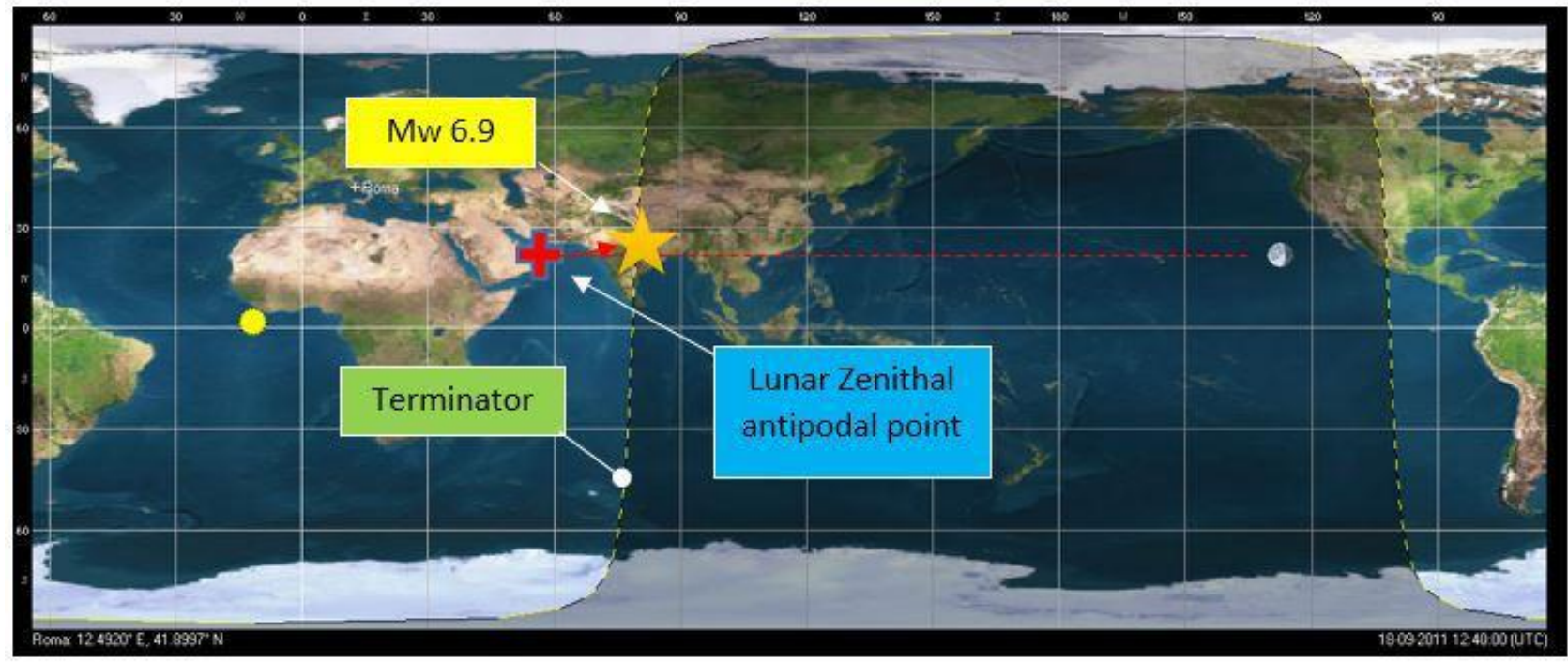

Fig.15 - EarthQuake Mw 6.9 - of 18 September 2011 - India-Nepal border region. In this case the earthquake occurred on the terminator, it took place very close to the antipodal point of the lunar zenith. Credits: Radio Emissions Project, USGS.

Mw 7.4 - October 21, 2011 - UTC Time: 17:57 - Kermadec Islands region, New Zealand - GPS: Latitude: 28.998 Longitude: -176.183 - Earthquake occurred as you can see from the map, in the terrestrial terminator area:

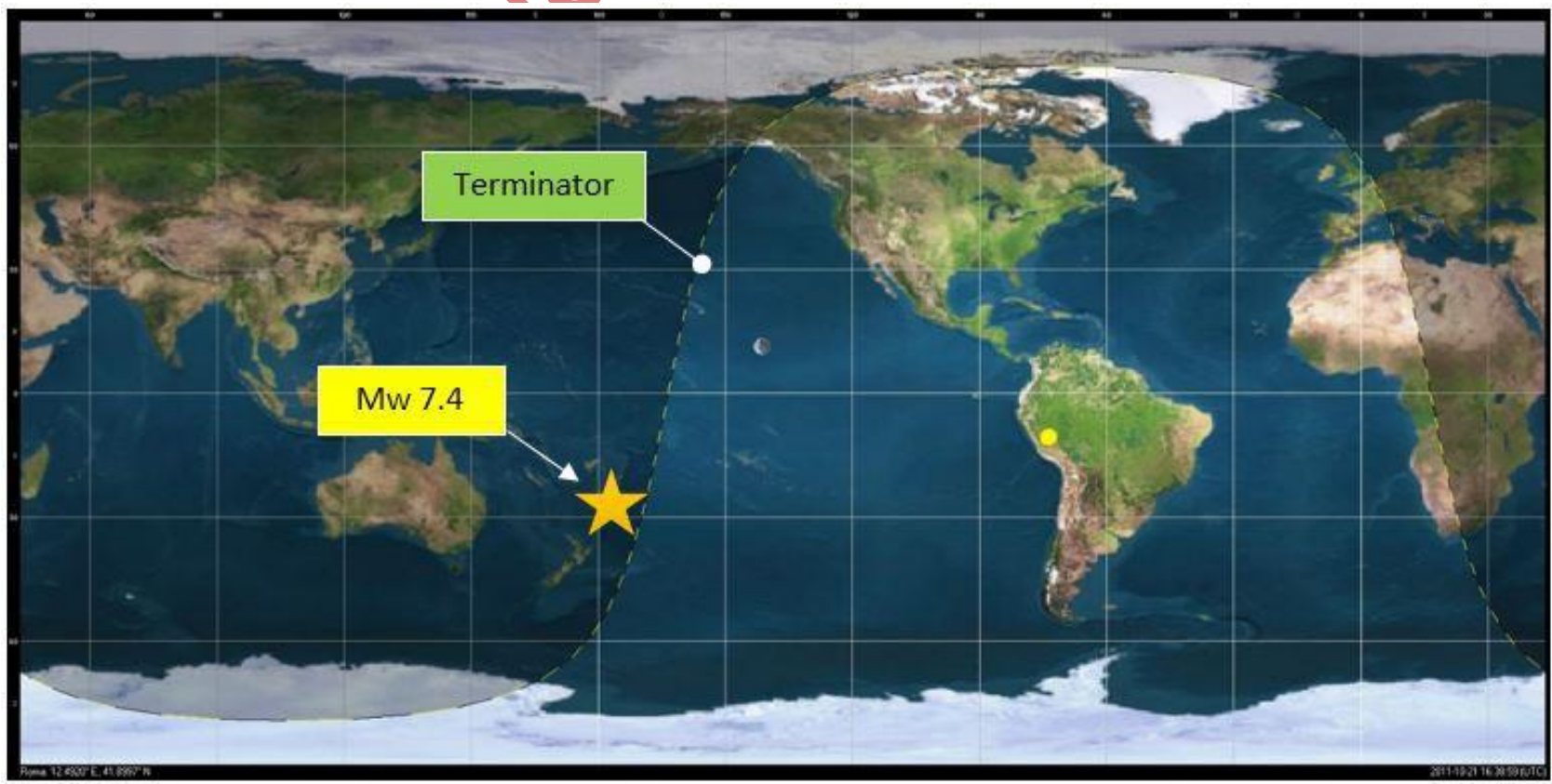

Fig.16-EarthQuake Mw 7.4 - of 21 October 2011 - Kermadec Islands. The earthquake in this case occurred in close correspondence of the terrestrial terminator. Credits: Radio Emissions Project, USGS. 
Mw 7.2 - January 10, 2012 - UTC Time: 18:36 - Off the west coast of northern Sumatra, Indonesia - GPS: Latitude: 2.452 - Longitude: 93.209.

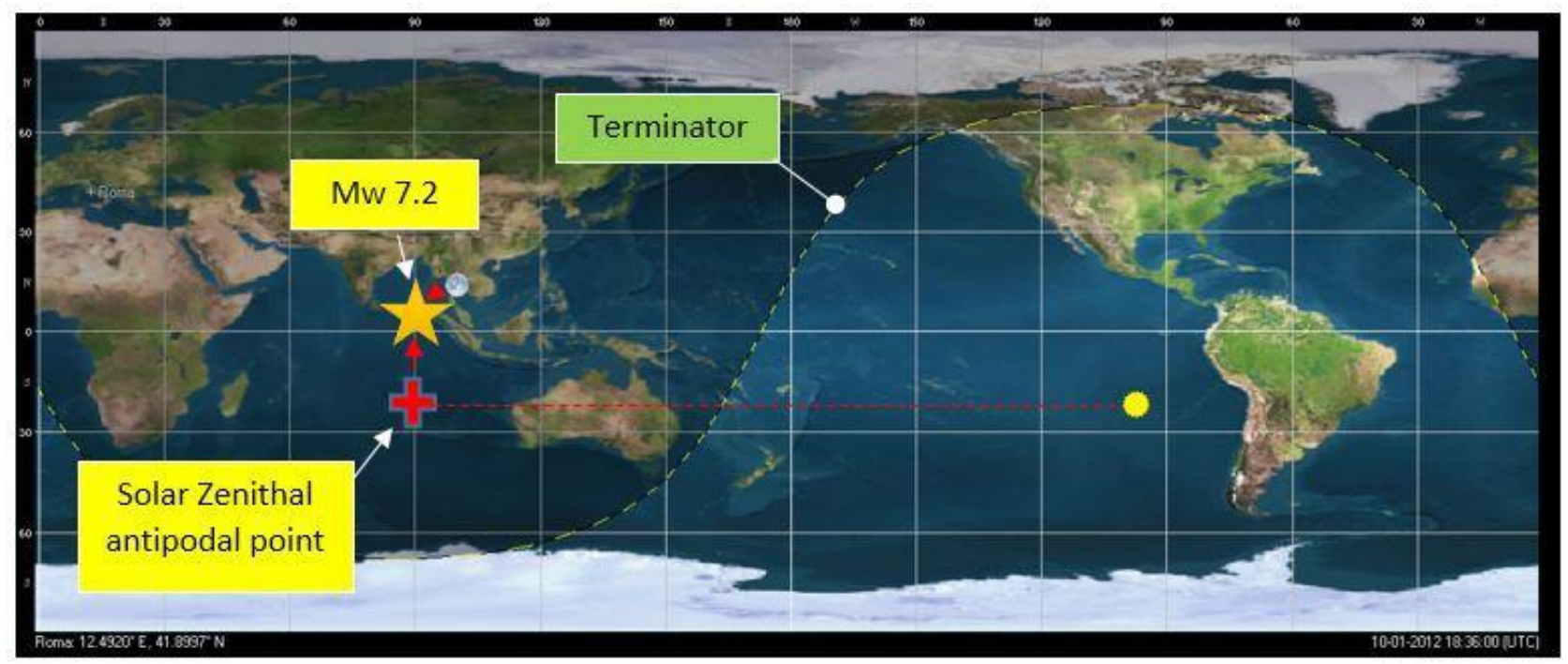

Fig.17 - EarthQuake Mw 7.2 - of 10 Jenuary 2012 - Sumatra, Indonesia. The earthquake occurred, on the lunar zenithal point, apochissima distance, as can be positive to observe and a short distance from the solar zenithal antipodal point. Furthermore, the position of the Sun and the Moon, are located opposite to the Earth surface, from two distinct and opposite points. Credits: Radio Emissions Project, USGS.

Mw 7.1 - February 2, 2012 - UTC Time: 13:34 - Vanuatu - GPS: Latitude: -17.766 - Longitude: 167.134.

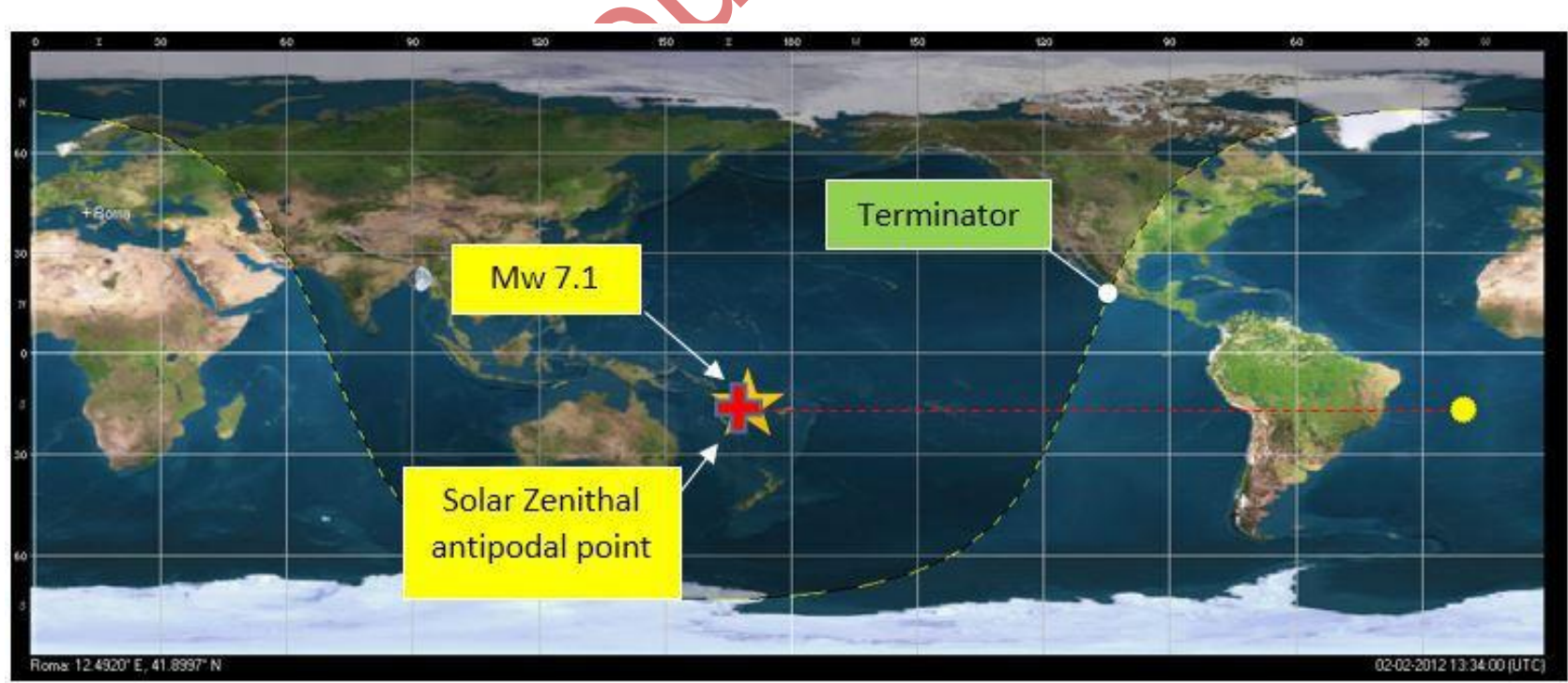

Fig.18 - EarthQuake Mw 7.1 - of 2 February 2012 - Vanuatu. The earthquake occurred on the Solar Zenithal Antipodal Point, in the center of the terrestrial area in the shadow. Credits: Radio Emissions Project, USGS. 
Mw 6.7 - February 6, 2012 - UTC Time: 03:49 - Negros-Cebu region, Philippines - GPS: Latitude: 9.964 Longitude: 123.246

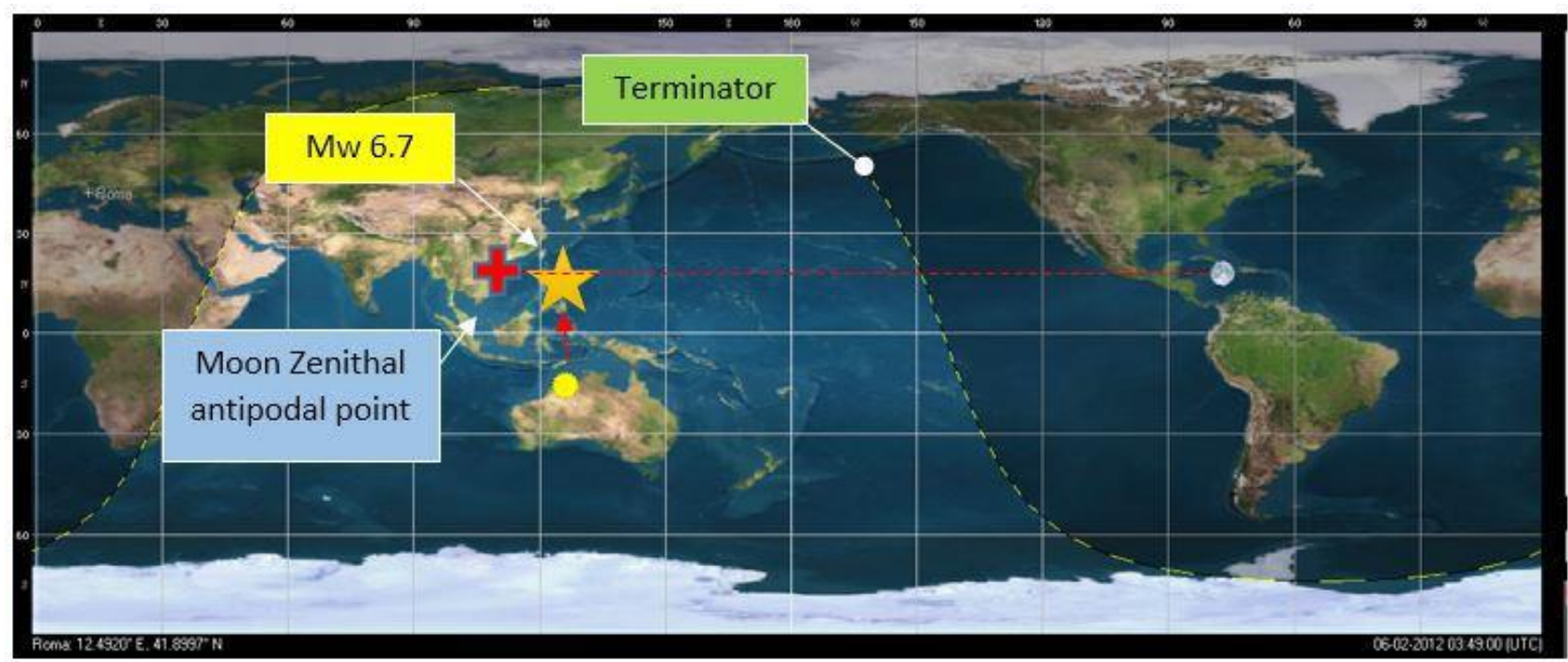

Fig.19- EarthQuake Mw 6.9 - of 6 February 2012 - Philippines. The earthquake occurred near the Moon Zenithal Antipodal Point. In this case the position of the Sun and the Moon, are found opposite, by the Earth surface from two distinct and opposite points. Credits: Radio Emissions Project, USGS.

Mw 7.4 - March 20, 2012 - UTC Time: 18:02 -Oaxaca, Mexico - GPS: Latitude: 16.662 - Longitude: -98.188.

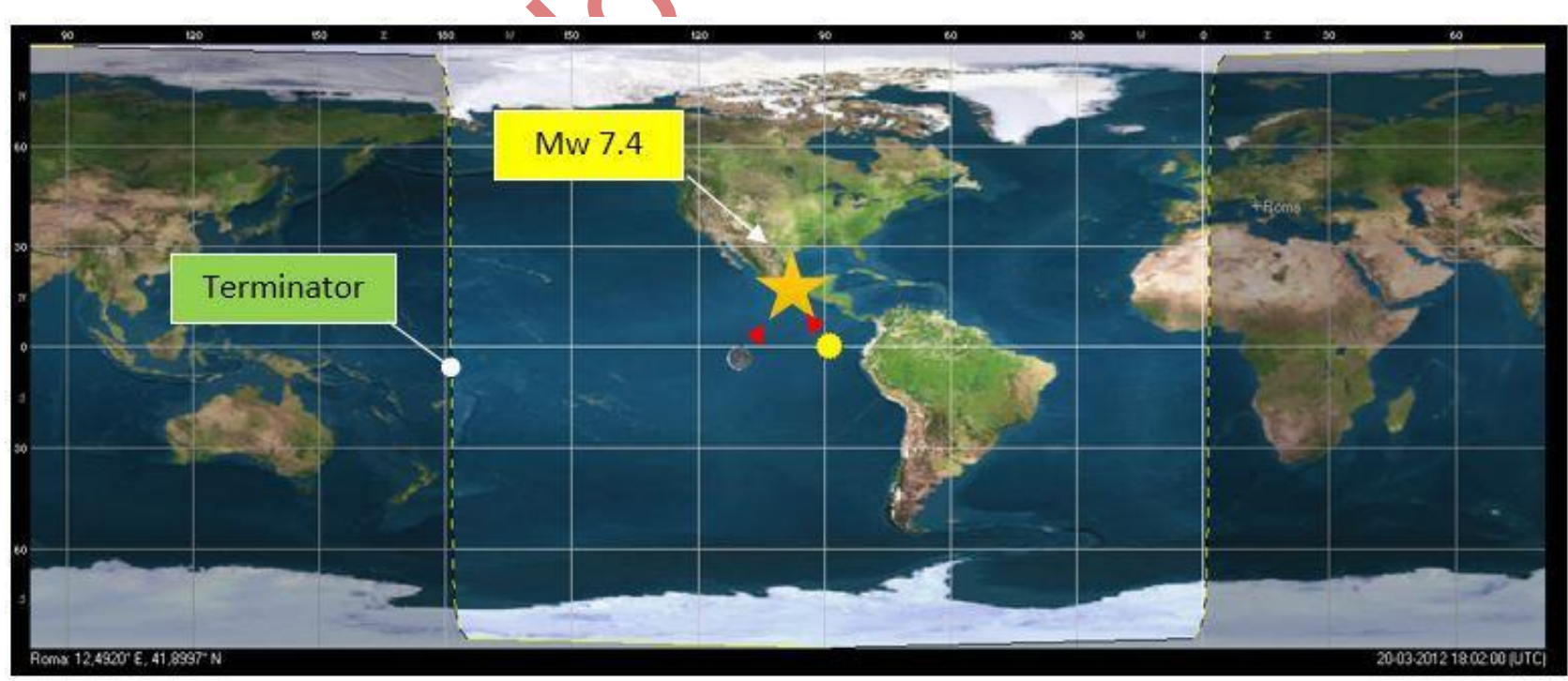

Fig.20 -EarthQuake Mw 7.4 - of 20 March 2012 - Oxaca, Mexico. The earthquake occurred near the Solar and Lunar Azimuthal Points. In this case the position of the Moon and the Sun are close together, both astronomical objects are found in the same direction and position, such as to determine a traction on the same part of the lithosphere. Credits: Radio Emissions Project, USGS. 
Volume 9 Issue 7 July 2021

Mw 7.1 - March 25, 2012 - UTC Time: 22:37 - Maule, Chile - GPS: Latitude: -35.183 - Longitude: -71.792.

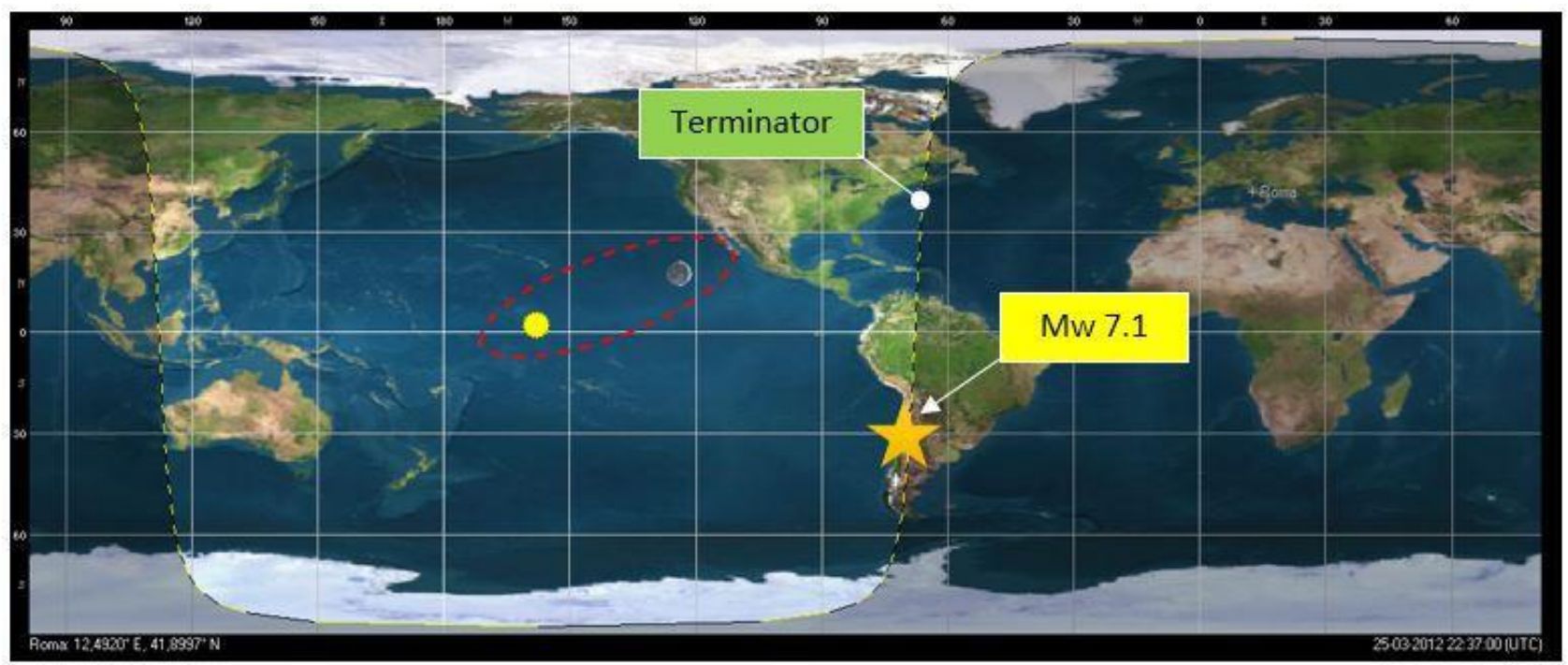

Fig.21 - EarthQuake Mw 7.1 - of 25 March 2012 - Chile. The earthquake occurred near the Earth Terminator. In this case the position of the Moon and the Sun are close together, both astronomical objects are found in the same direction and position, such as to determine a traction on the same part of the lithosphere. Credits: Radio Emissions Project, USGS.

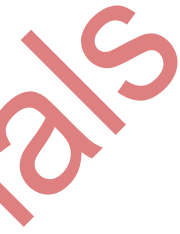

Mw 8.6 - April 11, 2012 - UTC Time: 08:38 - Off the west coast of northern Sumatra, Indonesia - GPS Latitude: 2.311-Longitude: 93.063.

2

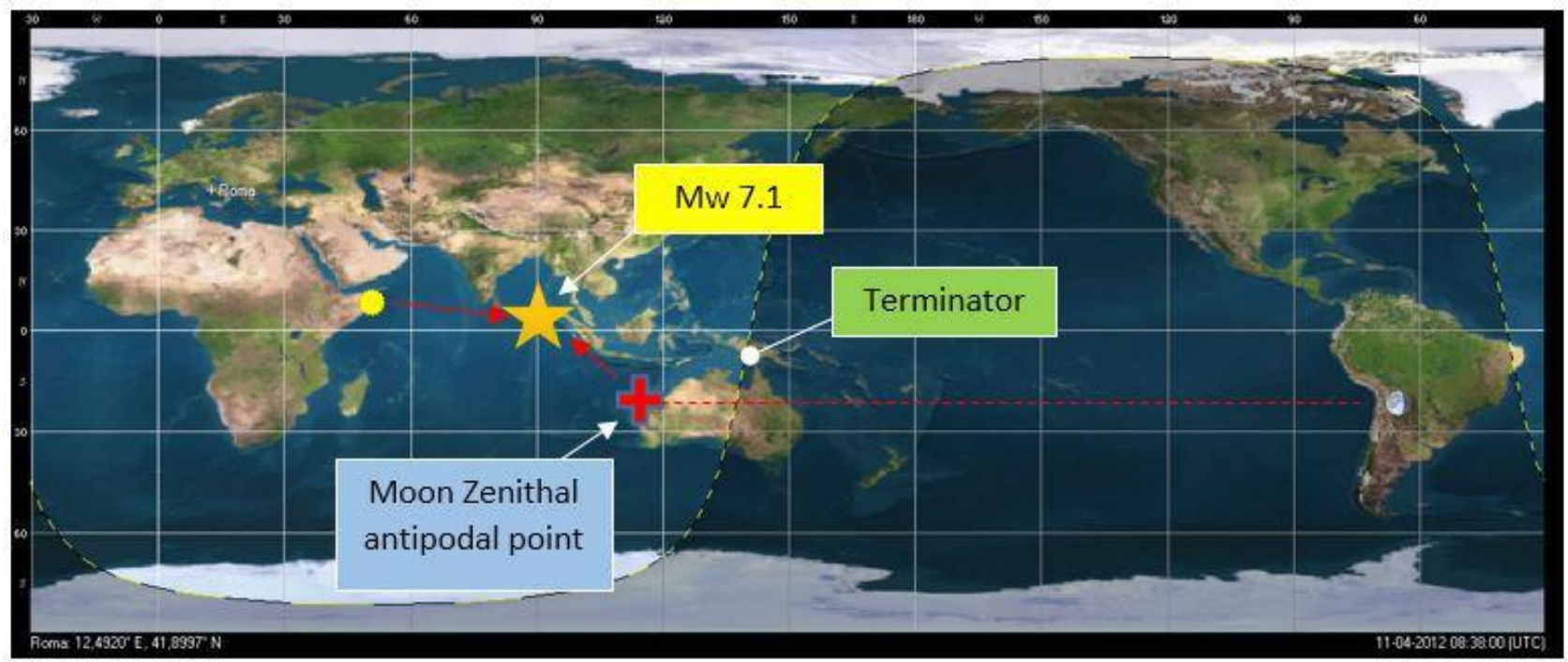

Fig.22 - EarthQuake Mw 8.6 - of 11 April 2012 - Sumatra, Indonesia. The earthquake occurred near the Lunar e Solar Azimuthal Antipodal Points. Credits: Radio Emissions Project, USGS. 
Mw 8.2 - April 11, 2012 - UTC Time: 10:43 - Off the west coast of northern Sumatra, Indonesia - GPS: Latitude: 0.773 - Longitude: 92.452.

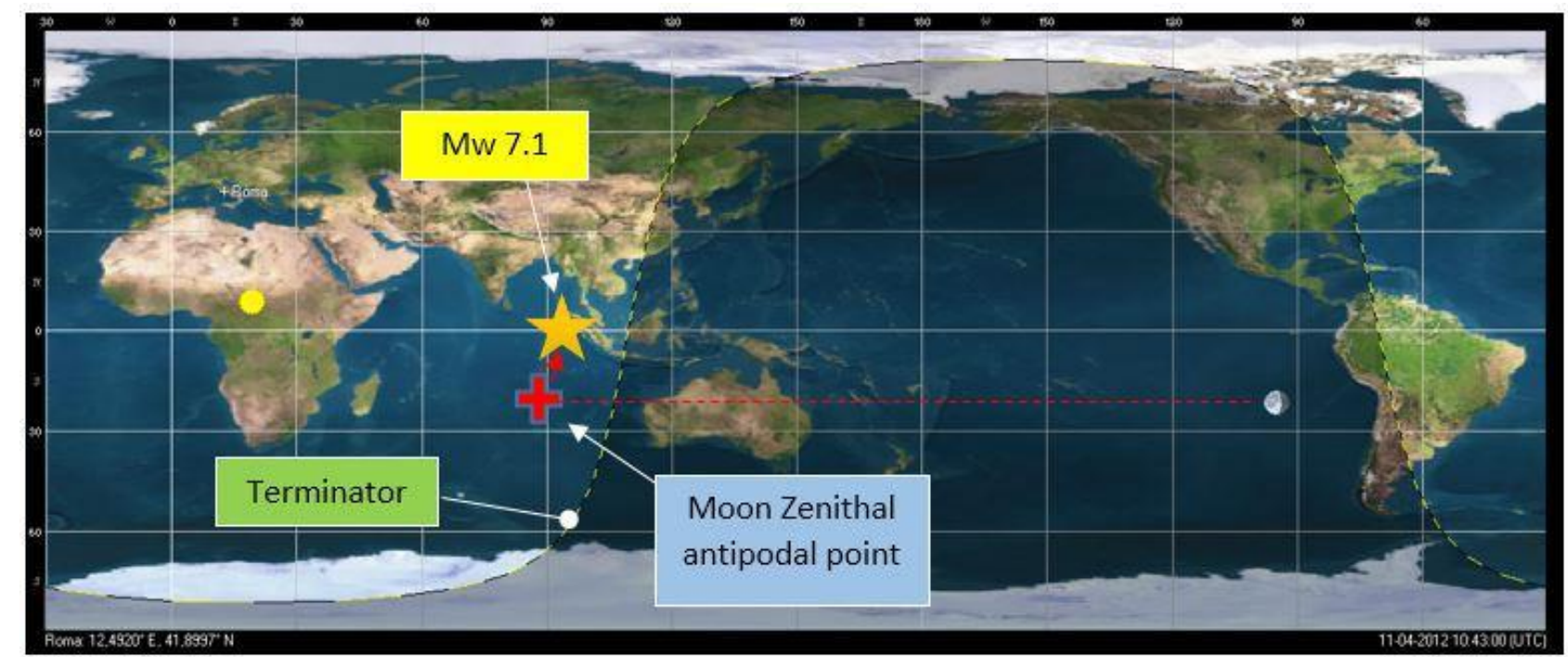

Fig.23 - EarthQuake Mw 8.2 - of 11 April 2012 - Sumatra, Indonesia. The earthquake occurred near the Lunar Antipodal Point and the Earth Terminator. Credits: Radio Emissions Project, USGS.

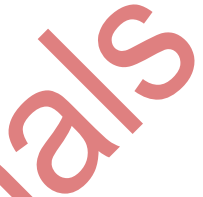

Mw 7.7 - August 14, 2012 - UTC Time: 02:59 - Sea of Okhotsk - GPS: Latitude: 49.784 - Longitude: 145.126.

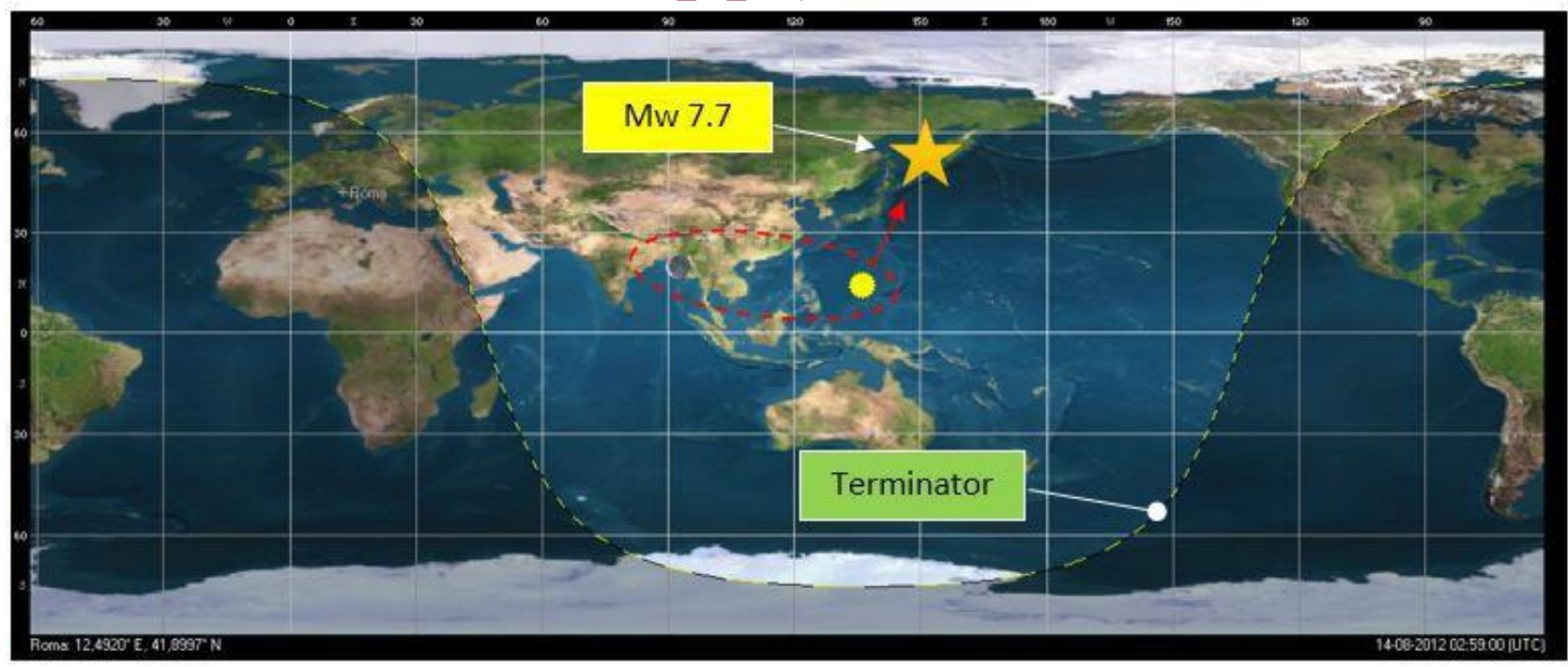

Fig.24 - EarthQuake Mw 7.7 - of 14 August 2012 - Okhotsk. The earthquake occurred near the Solar Azimuthal Point. The Sun and the Moon, both are present in the illuminated area and therefore the gravitational interaction is much more intense than normal. Credits: Radio Emissions Project, USGS. 
Volume 9 Issue 7 July 2021

Mw - 7.6 - August 31, 2012 - UTC Time: 12:47 - Philippine Islands region - GPS: Latitude: 10.838 Longitude: 126.704.

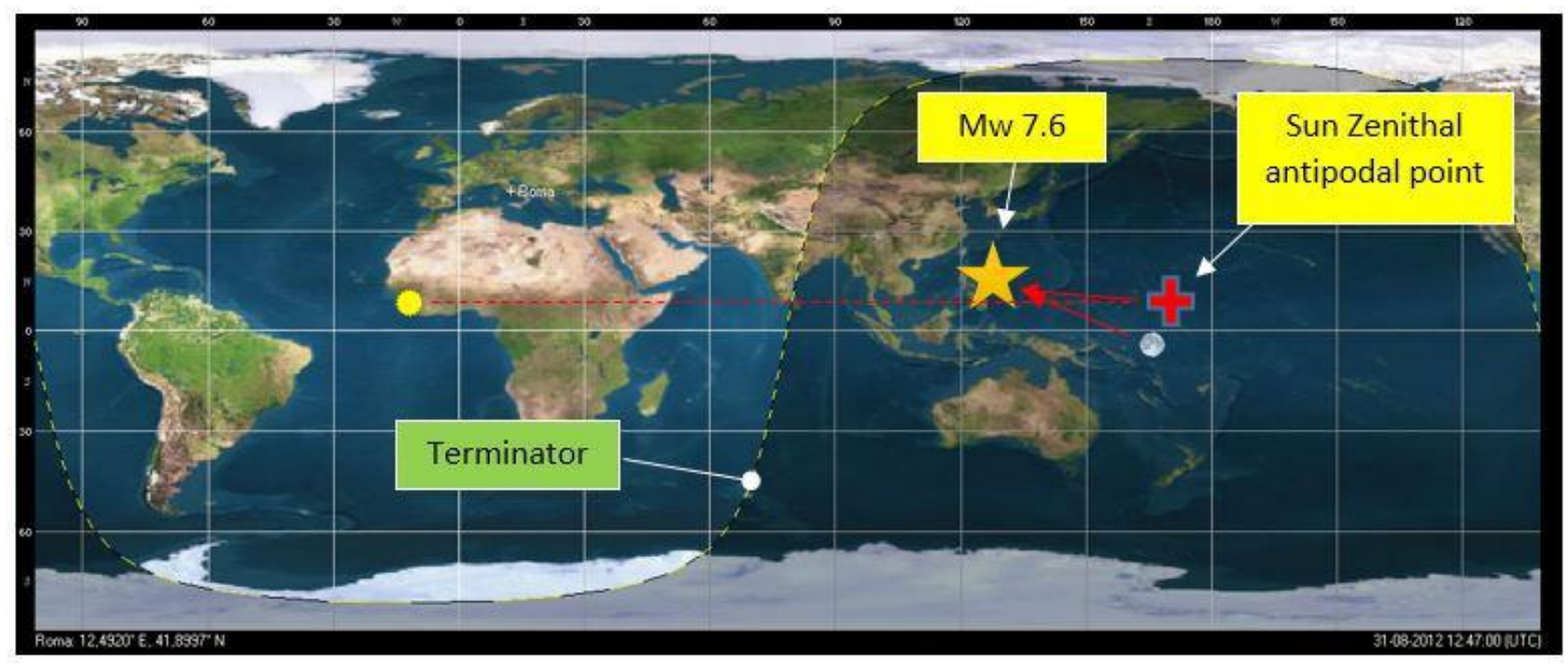

Fig.25 - EarthQuake Mw 7.6 - of 31 August 2012 - Philippine. In this case is the position of the Sun and the Moon, which are opposed to the earth's surface, have gravitationally influenced the traction of the earth's surface, pushing from two opposite points, as happens when a rubber band tends. Credits: Radio Emissions Project, USGS.

Mw 7.3 - September 30, 2012 - UTC Time: 16:31 - Colombia - GPS: Latitude: 1.916 - Longitude: -76.355.

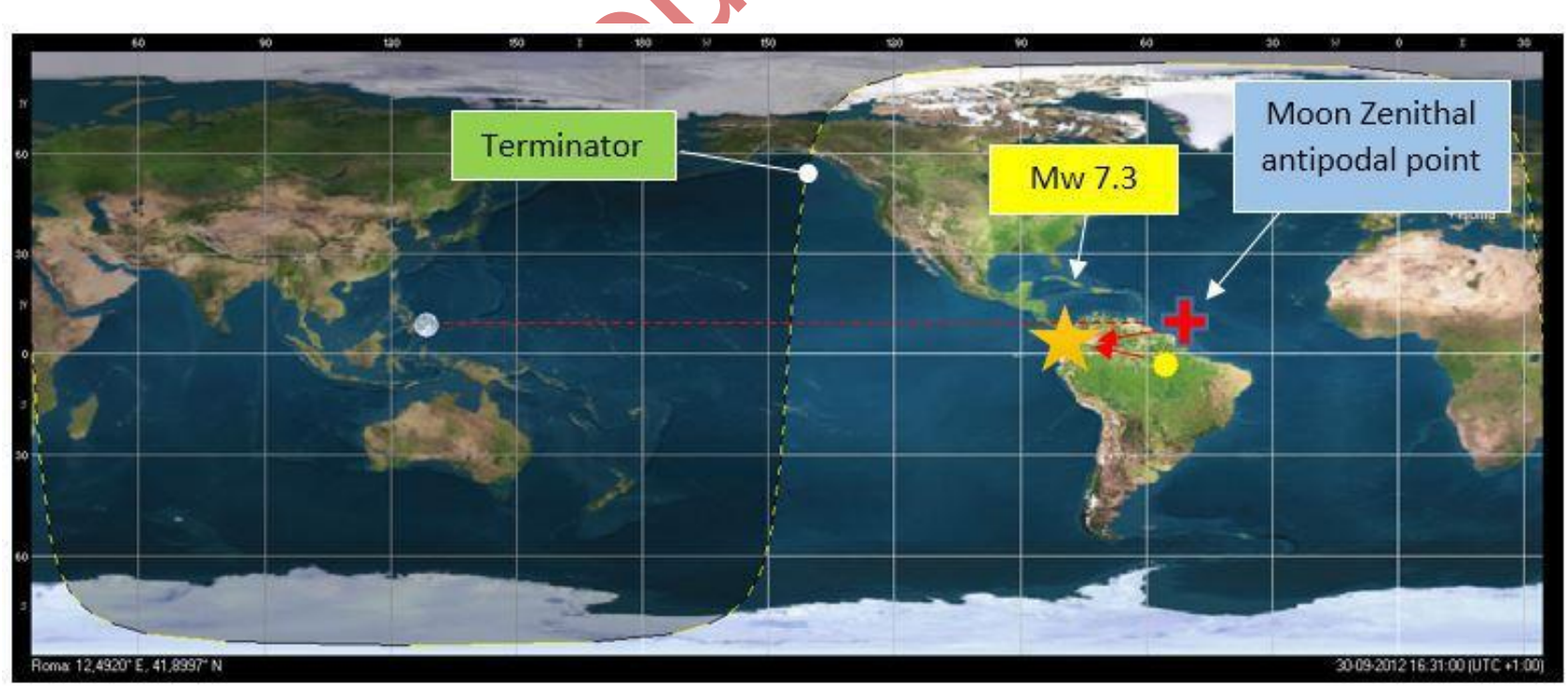

Fig.26 - - EarthQuake Mw 7.3 - of 30 September 2012 - Colombia. In this case is the position of the Sun and the Moon, which are opposed to the earth's surface, have gravitationally influenced the traction of the earth's surface, pushing from two opposite points, as happens when a rubber band tends. Credits: Radio Emissions Project, USGS. 
Volume 9 Issue 7 July 2021

Mw 7.7 - October 28, 2012 - UTC Time: 03:04 - Queen Charlotte Islands region, Canada - GPS: Latitude: 52.769 - Longitude: -131.927.

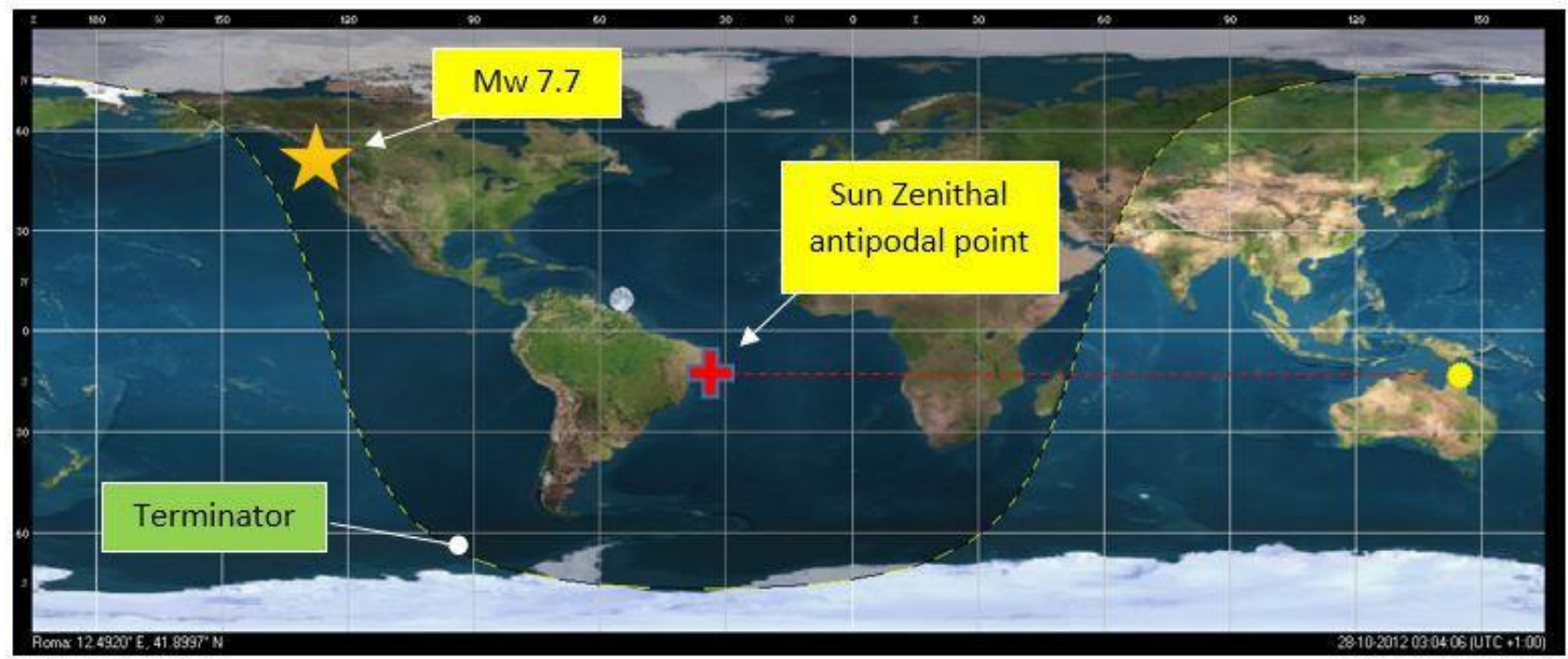

Fig.27 - EarthQuake Mw 7.7 - of 28 October 2012 - Canada. In this case the earthquake occurred along the terrestrial terminator. The position of the Sun and the Moon show that in the preparatory stages of the earthquake, the stars were in opposition from our planetary body. Credits: Radio Emissions Project, USGS.

Mw 7.4 - November 7, 2012 - UTC Time: 16:35 - Offshore Guatemala - GPS: Latitude: 14.083 Longitude: -91.916.

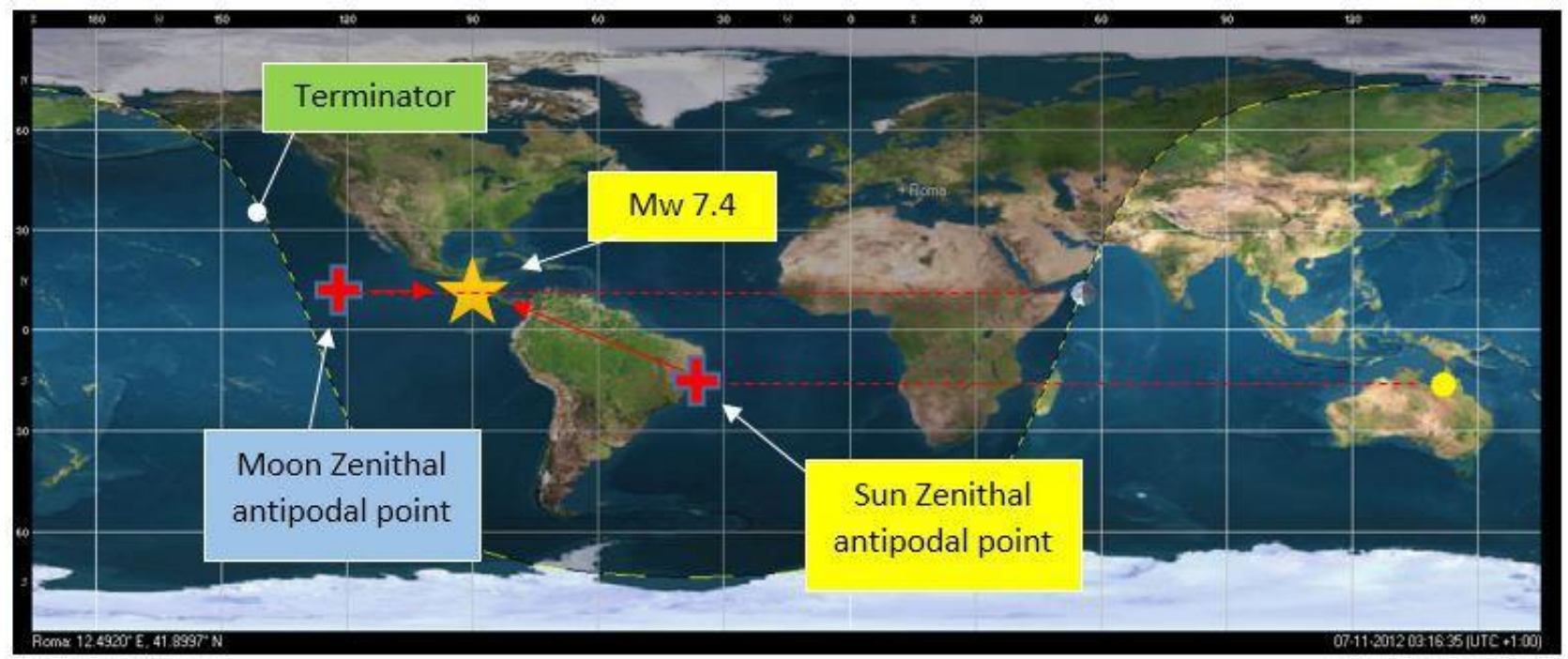

Fig.28 - EarthQuake Mw 7.4 - of 7 November 2012 - Guatemala. The earthquake occurred near the the lunar antipodal zenith point, and in restricted proximity to the solar antipodal azimutal point. Credits: Radio Emissions Project, USGS. 
Volume 9 Issue 7 July 2021

Mw 7.3 - December 7, 2012 - UTC Time: 08:18 - Off the east coast of Honshu, Japan - GPS: Latitude: 37.889 Longitude: 144.090.

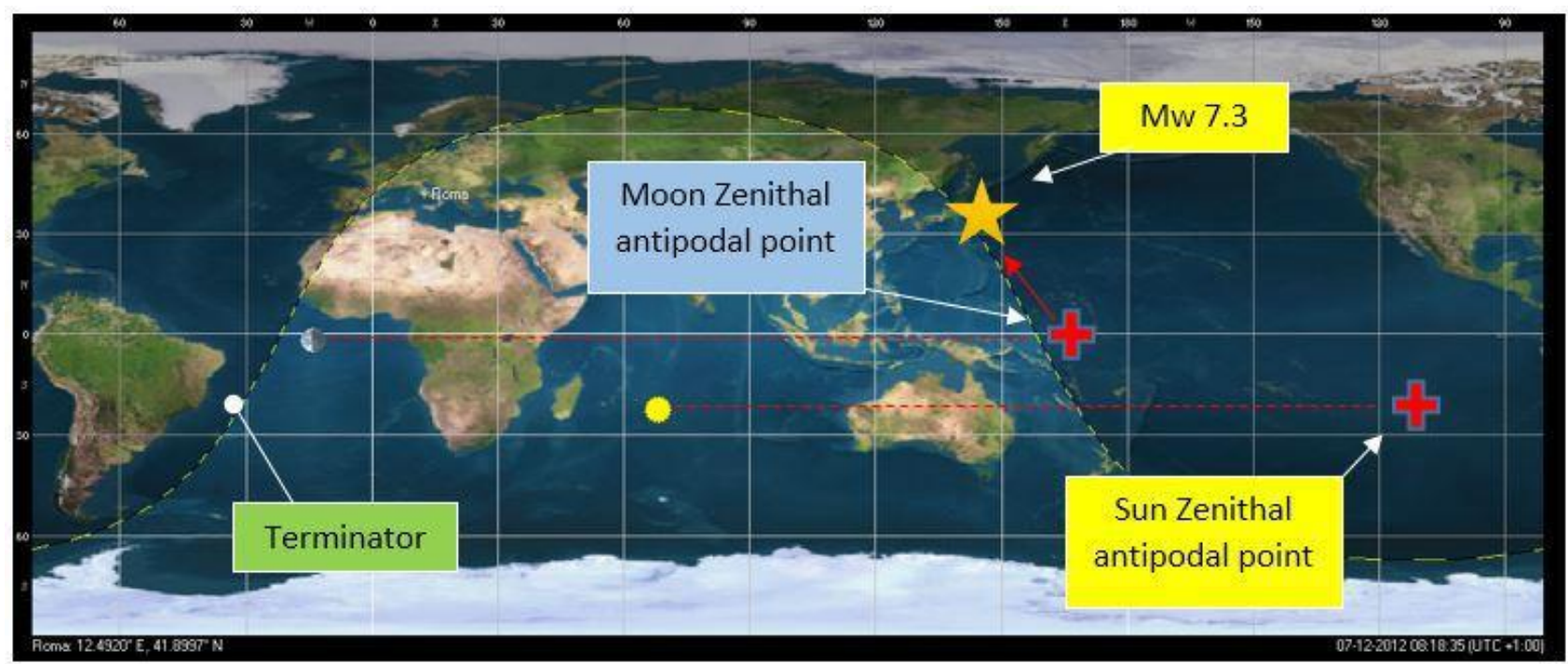

Fig.29 - EarthQuake Mw 7.3 - of 7 December 2012 - Japan. The earthquake occurred near the the lunar antipodal zenith point, and on the terrestrial terminator. Credits: Radio Emissions Project, USGS.

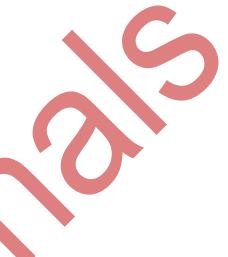

Mw 7.4 - May 23, 2013 - UTC Time: 17:19 - South of the Fiji Islands - GPS: Latitude: -23.025 - Longitude: 177.109.

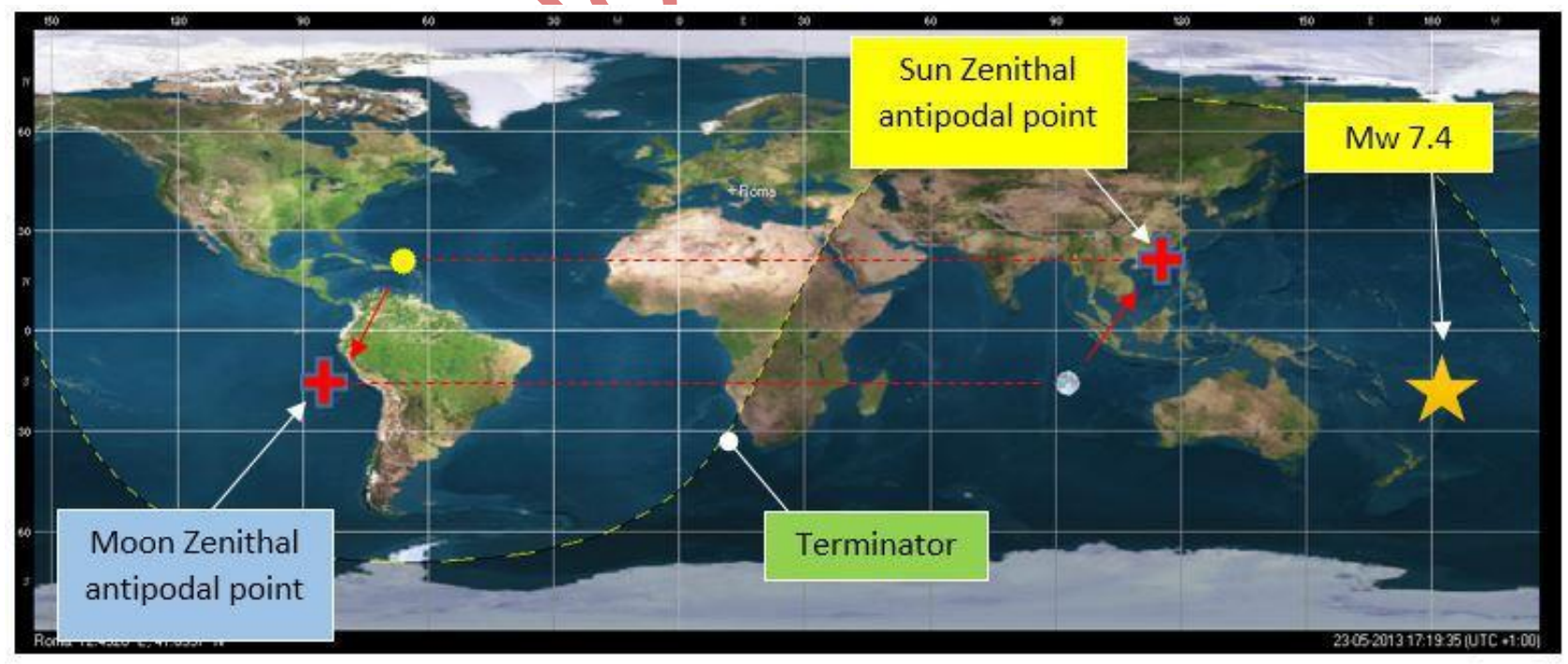

Fig.30 - EarthQuake Mw 7.3 - of 23 May 2013 - Fiji Islands. The earthquake occurred at the center of the area in the shadow of the earth's surface, in the moments in which the Sun and the Moon were opposed to the planetary body, such as to induce a strong opposite traction, lithosphheric surface. Credits: Radio Emissions Project, USGS. 
Mw 7.7 - September 24, 2013 - UTC Time: 11:29- Pakistan - GPS: Latitude: 26.971 - Longitude: 65.520.

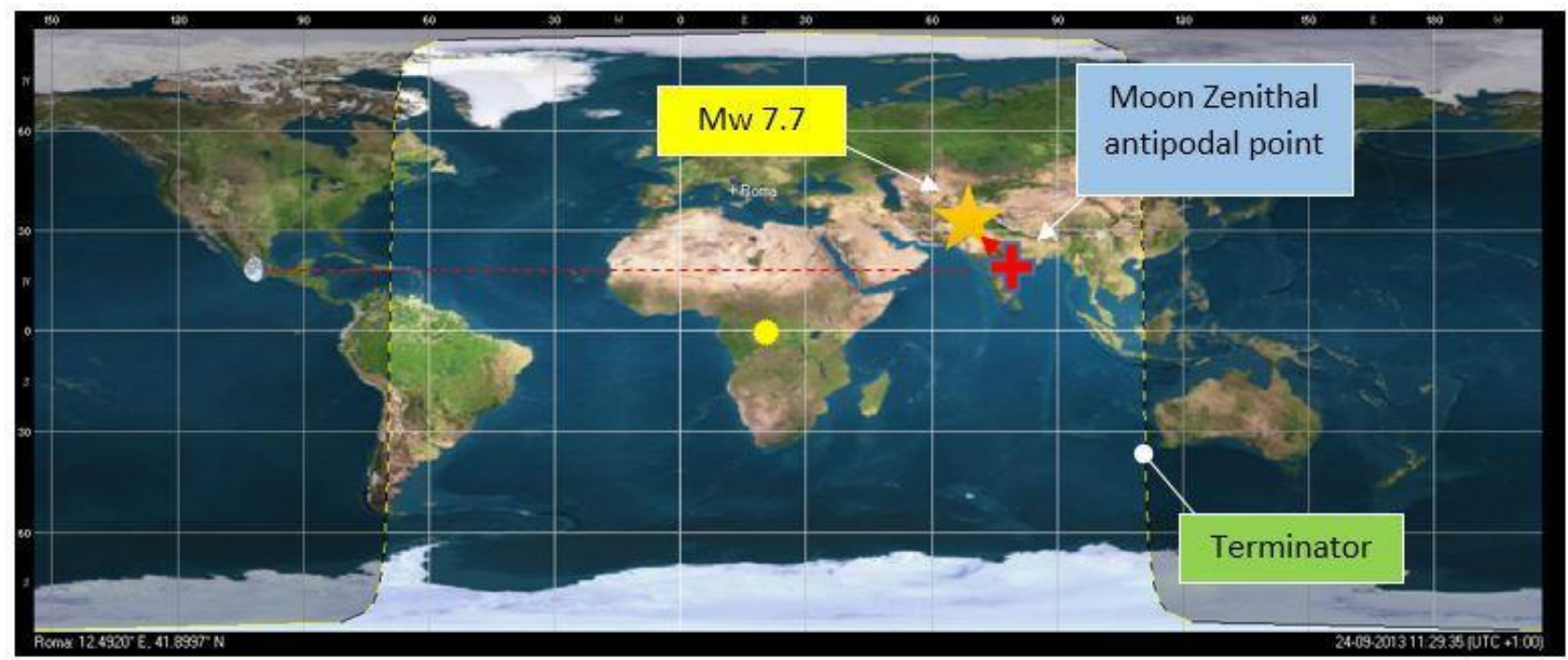

Fig.31 - EarthQuake Mw 7.3 - of 24 September 2013 - Pakistan. The earthquake occurred in the vicinity of the lunar antipodal azimuthal point, it is evident as such gravitational points determine triggered on areas with high tectonic stress. Credits: Radio Emissions Project, USGS.

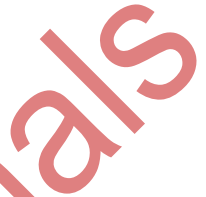

Mw 7.7 - November 17, 2013 - UTC Time: 09:04 - Scotia Sea - GPS: Latitude: -60.274 - Longitude: -46.401.

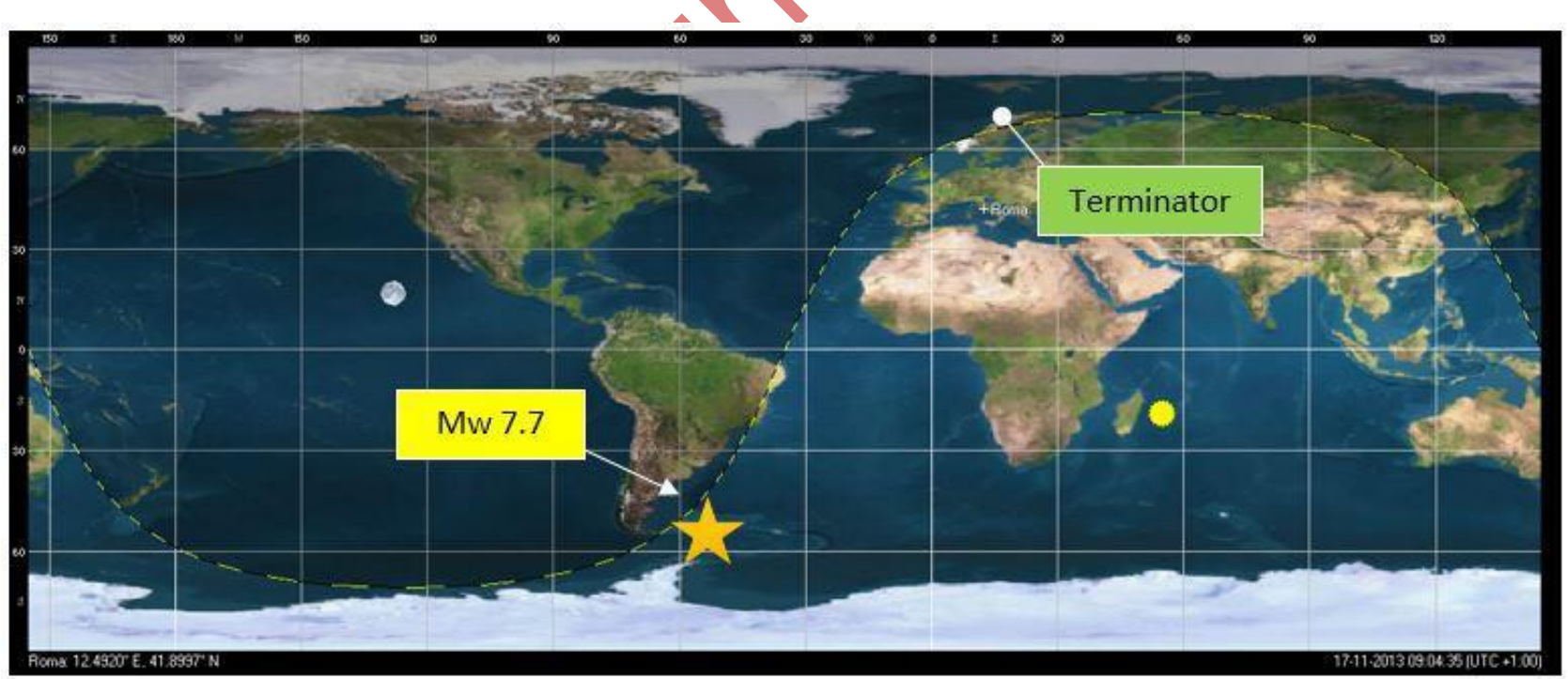

Fig.32 - EarthQuake Mw 7.7 - of 17 November 2013 - Scotia Sea. The earthquake occurred on the terrestrial terminator, with Sun and Moon in opposition. In this case the gravitational traction was very intense, for the azimutal position of the celestial bodies, arranged in the center of the hemispheres (the one illuminated and the one in shadow). Credits: Radio Emissions Project, USGS. 
Mw 8.2 - April 1, 2014 - UTC Time: 23:46 - Near the coast of Tarapacá, Chile - GPS: Latitude: -19.642 Longitude: -70.817.

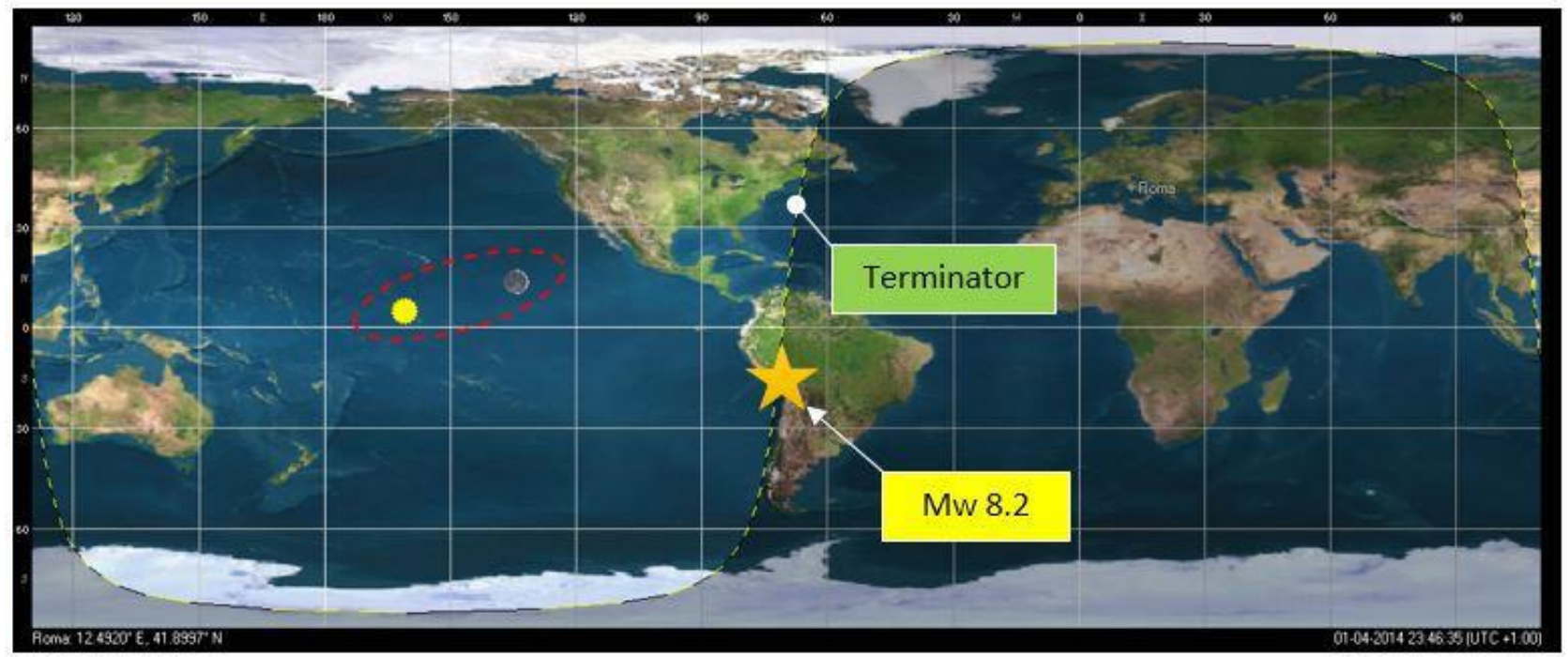

Fig.33- EarthQuake Mw 7.7 - of 1 April 2014 - Chile. The strong Chilean earthquake, occurred precisely on the terminator, in this case the celestial bodies (sun and moon) were in the direction of the illuminated hemisphere, such as to provide a greater gravitational boost, in the same direction. It is hypothesible that on the terminator, this force has acted more decisively, relaxing (by traction) the lithosphere and triggering the earthquake. Credits: Radio Emissions Project, USGS.

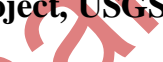

Mw 7.6 - April 12, 2014 - UTC Time: 20:14 - Solomon Islands - GPS: Latitude: -11.315 - Longitude: 162.211.

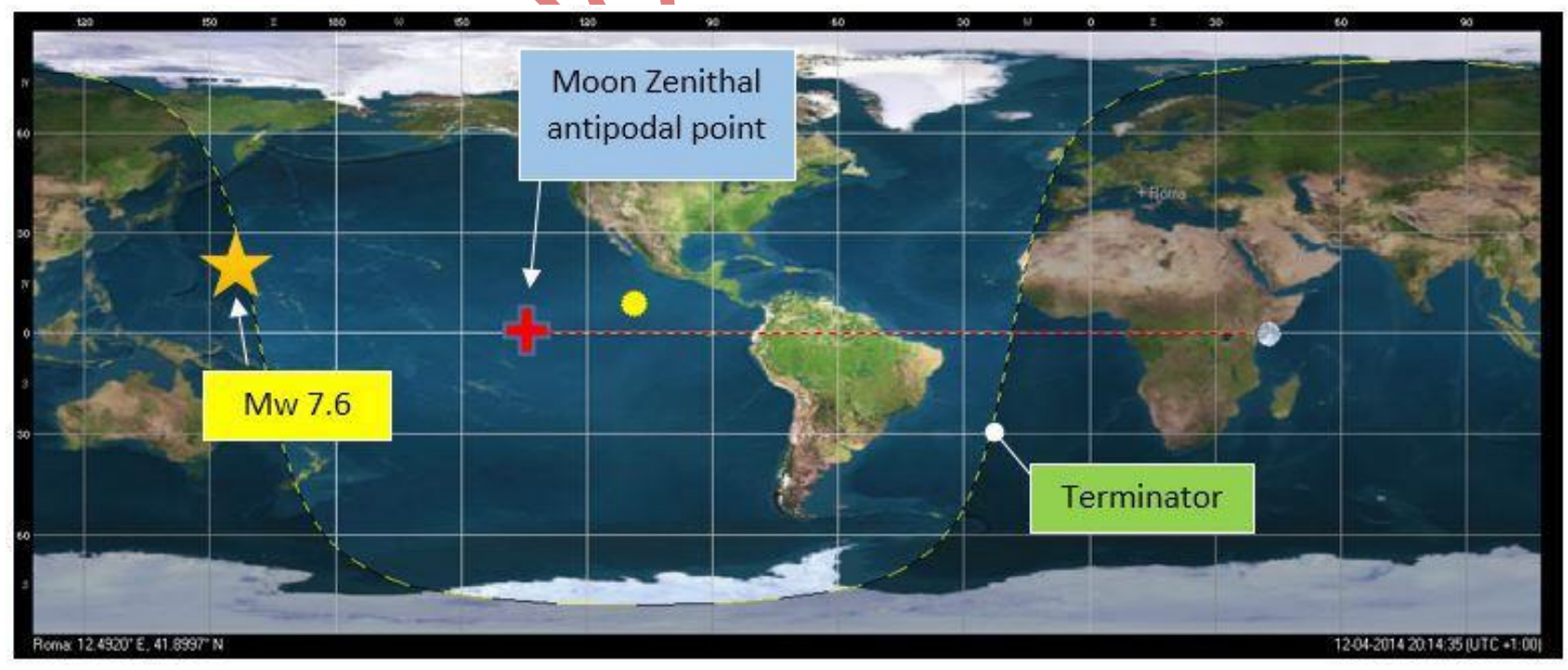

Fig.34 - EarthQuake Mw 7.6 - of 12 April 2014 - Solomon Islands. In this case the strong earthquake took place on the terminator, while the celestial bodies were arranged almost in perfect opposition, both on the illuminated hemisphere and the one in shadow. The coating force of the lithosphere along the terminator was particularly intense. Credits: Radio Emissions Project, USGS. 
Mw 7.9 - June 23, 2014 - UTC Time:20:53 - Rat Islands, Aleutian Islands, Alaska, United States - GPS: Latitude: 51.797 - Longitude: 178.760.

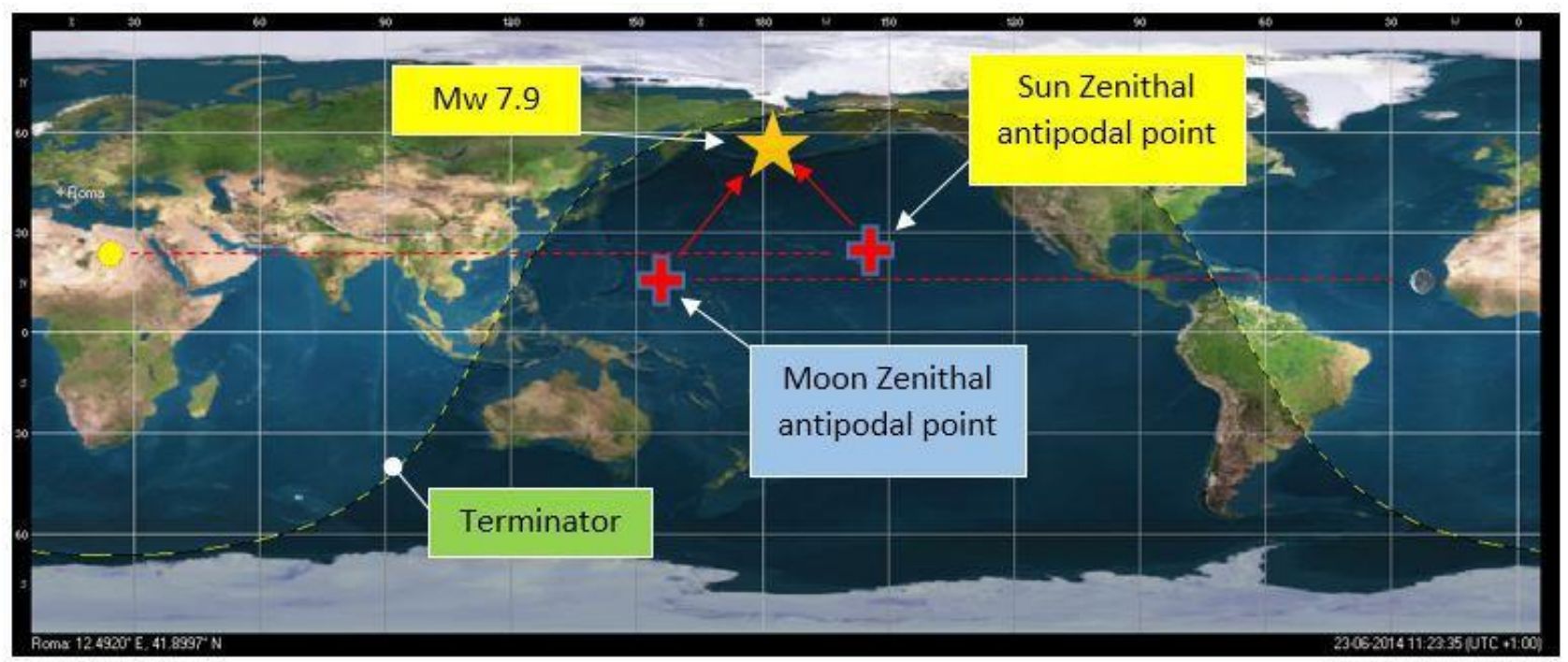

Fig.35 - EarthQuake Mw 7.9 - of 23June 2014 - Rat Islands, Aleutian Islands, Alaska, United States. In this case the earthquake took place very close to the terrestrial terminator and with the Moon Zenithal Antipodal Point and Sun Zenithal Antipodal Point, very close to the seismic epicenter. Credits: Radio Emissions Project, USGS.

Mw 7.3 - October 14, 2014 - UTC Tile: 03:51 - Offshore El Salvador - GPS: Latitude: 12.526 - Longitude: 88.123.

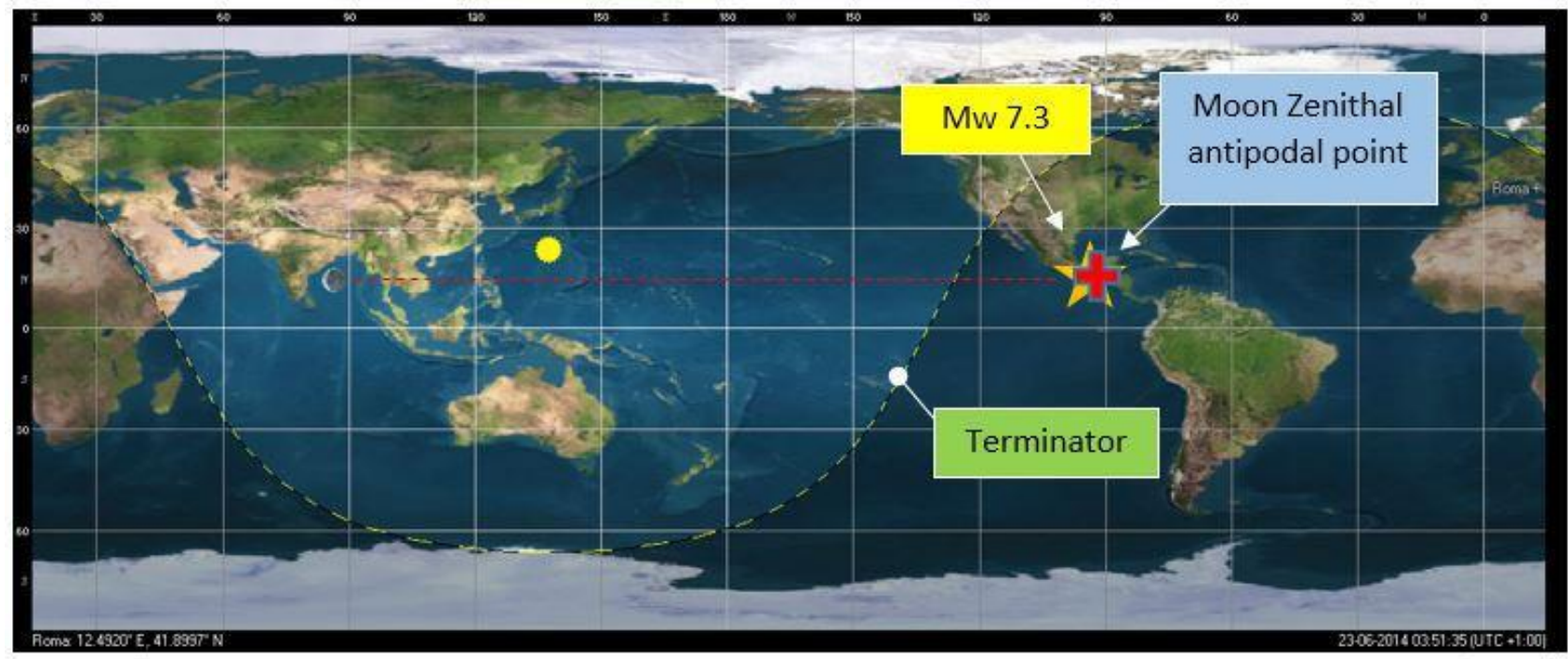

Fig.36 - EarthQuake Mw 7.6 - of 14 October 2014 - Offshore El Salvador. In this case the earthquake occurred close to the terrestrial terminator, but practically superimposed on the Moon Zenithal Antipodal Point. Credits: Radio Emissions Project, USGS. 
Volume 9 Issue 7 July 2021

Mw 7.8 - April 25, 2015 - UTC Time: 06:11 - Nepal - GPS: Latitude: 28.147 - Longitude: 84.708.

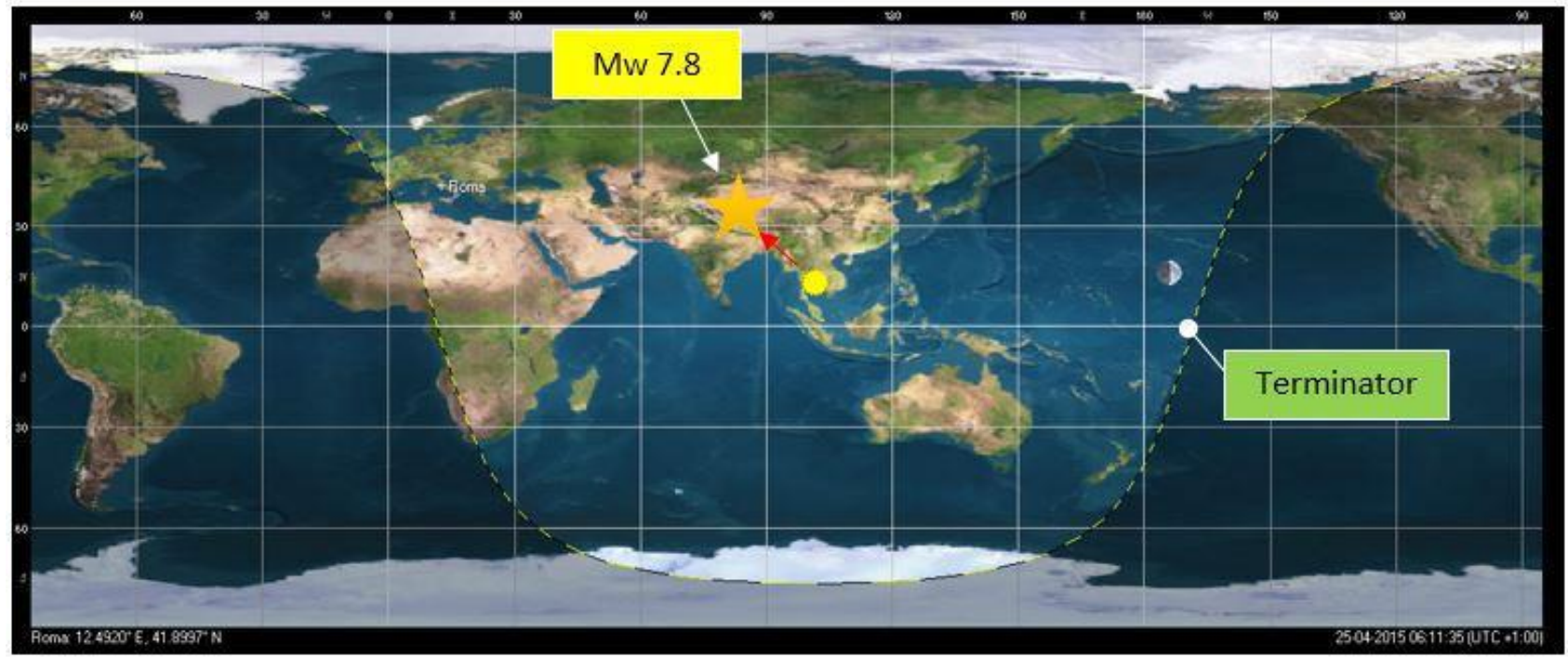

Fig.37 - EarthQuake Mw 7.6 - of 25 April 2015 - Nepal. In this case, the earthquake occurred very quickly from the Zun Zenithal Poin. Credits: Radio Emissions Project, USGS.

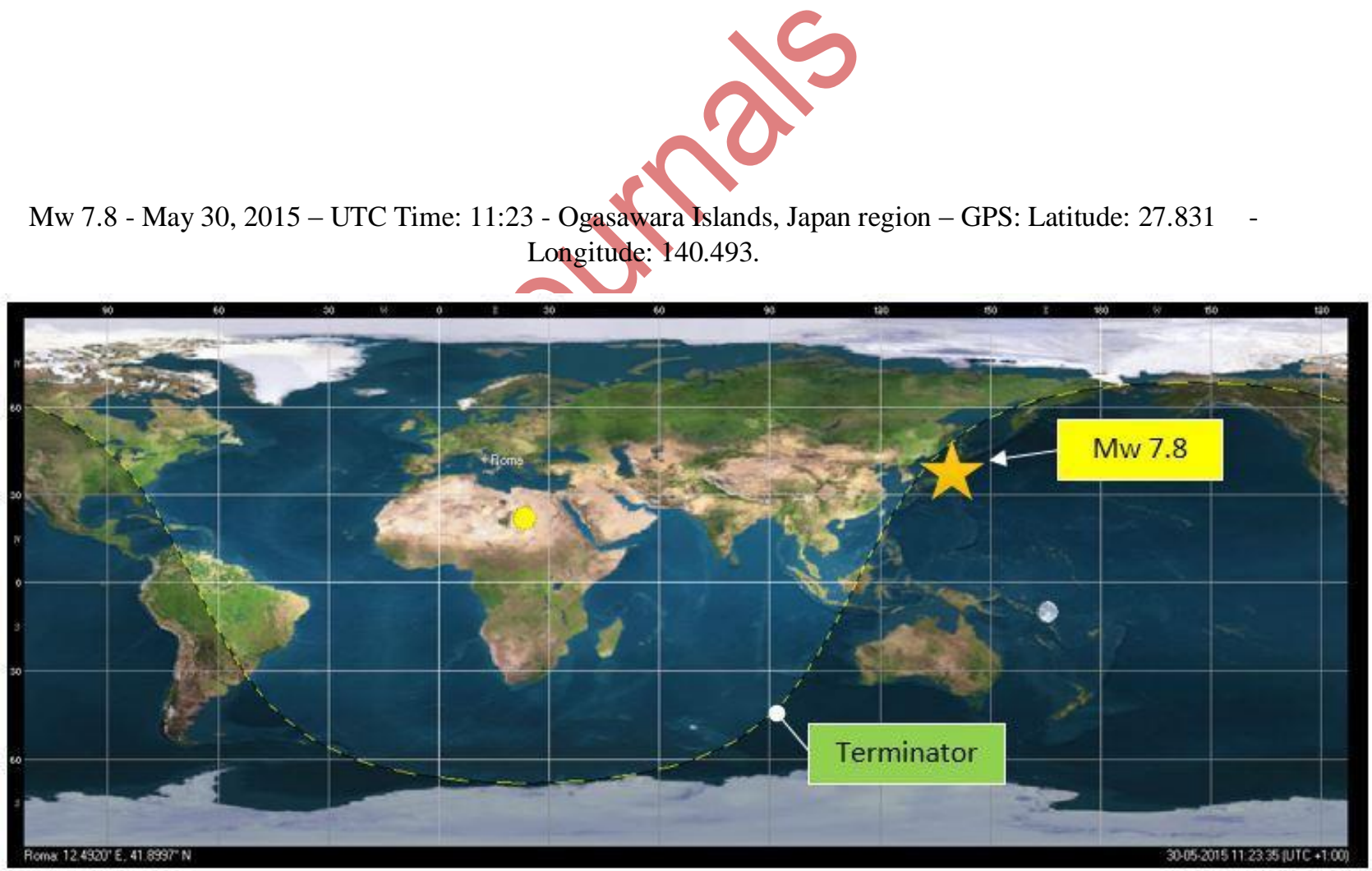

Fig.38 - EarthQuake Mw 7.8 - of 30 May 2015 - Japan region. In this case the earthquake has occurred almost on the terrestrial terminator. Credits: Radio Emissions Project, USGS. 


\section{SOME EXAMPLES OF RECENT EARTHQUAKES}

Mw 7.4 - March 4, 2021 - UTC Time: 17:41:25 - Kermadec Islands, New Zealand - GPS: Latitude: $29.613^{\circ} \mathrm{S}$ Longitude: $177.843^{\circ} \mathrm{W}$.

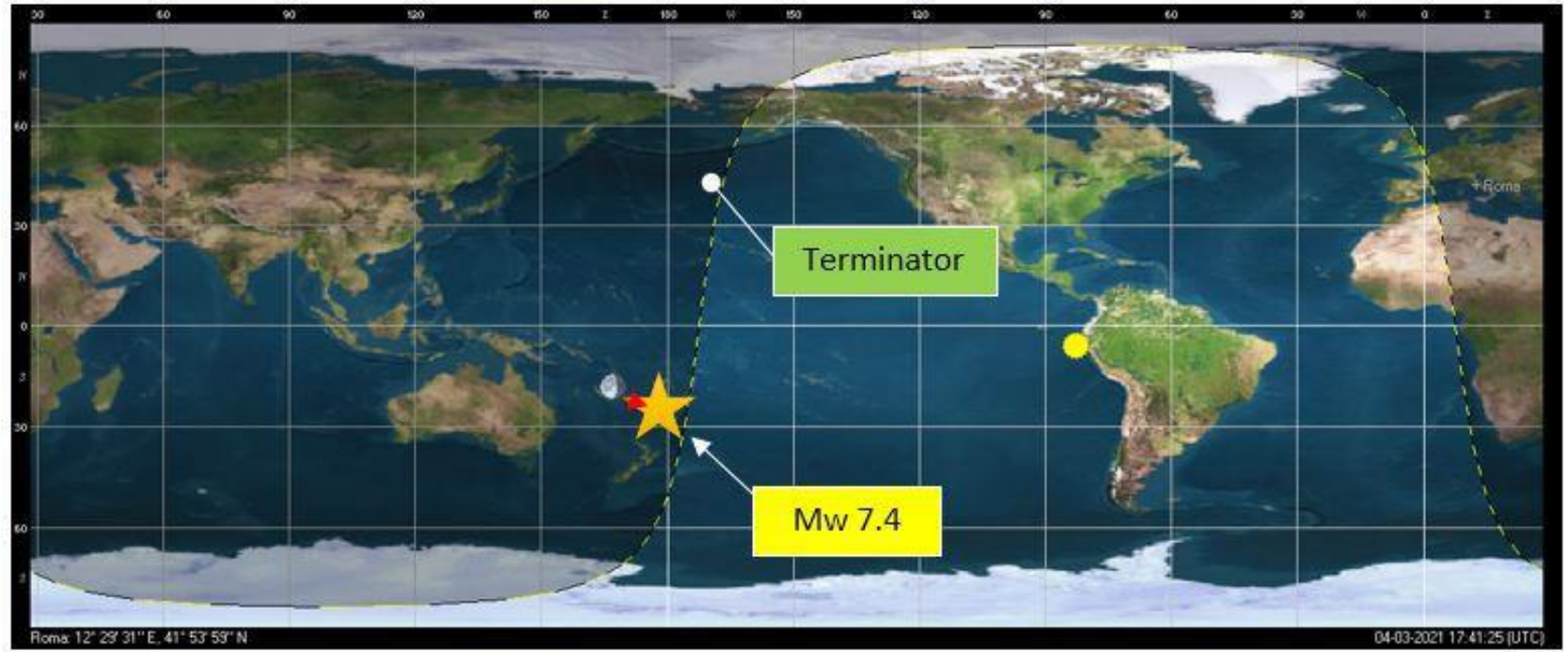

Fig.39 - EarthQuake Mw 7.4 - of 4 March 2021 - Kermadec Islands region. This earthquake occurred, as can be observed, at the terrestrial terminator and in close proximity to the lunar zenith. On the map, the time is displayed in Italian local hour, not in UTC but in LT. Credits: Radio Emissions Project, USGS.

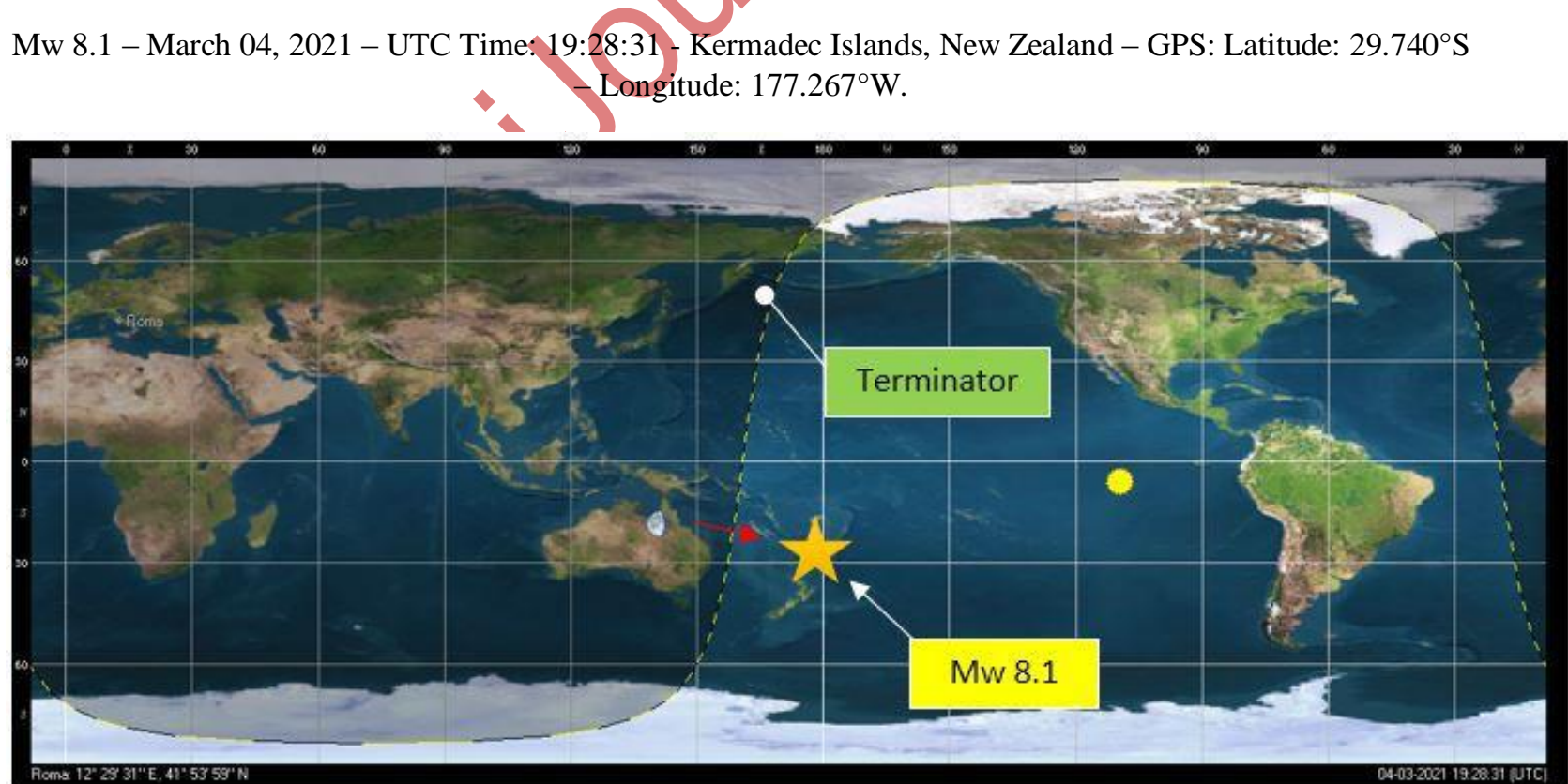

Fig.40 - EarthQuake Mw 8.1 - of 4 March 2021 - Kermadec Islands region. This earthquake occurred not far from the terrestrial terminator and a short distance from the lunar zenith. It has also occurred at a short time distance from the strong earthquake of magnitude Mw 7.3 verified in the same area, when the terrestrial terminator was superimposed in this region and a very short distance from the lunar zenith. On the map, the time is displayed in Italian local hour, not in UTC but in LT. Credits: Radio Emissions Project, USGS. 
Mw 7.2 - March 20, 2021 - UTC Time: 09:09:00 - 34 km E of Ishinomaki, Japan - GPS: Latitude: $38.400^{\circ} \mathrm{N}$ Longitude: $141.700^{\circ} \mathrm{E}$.

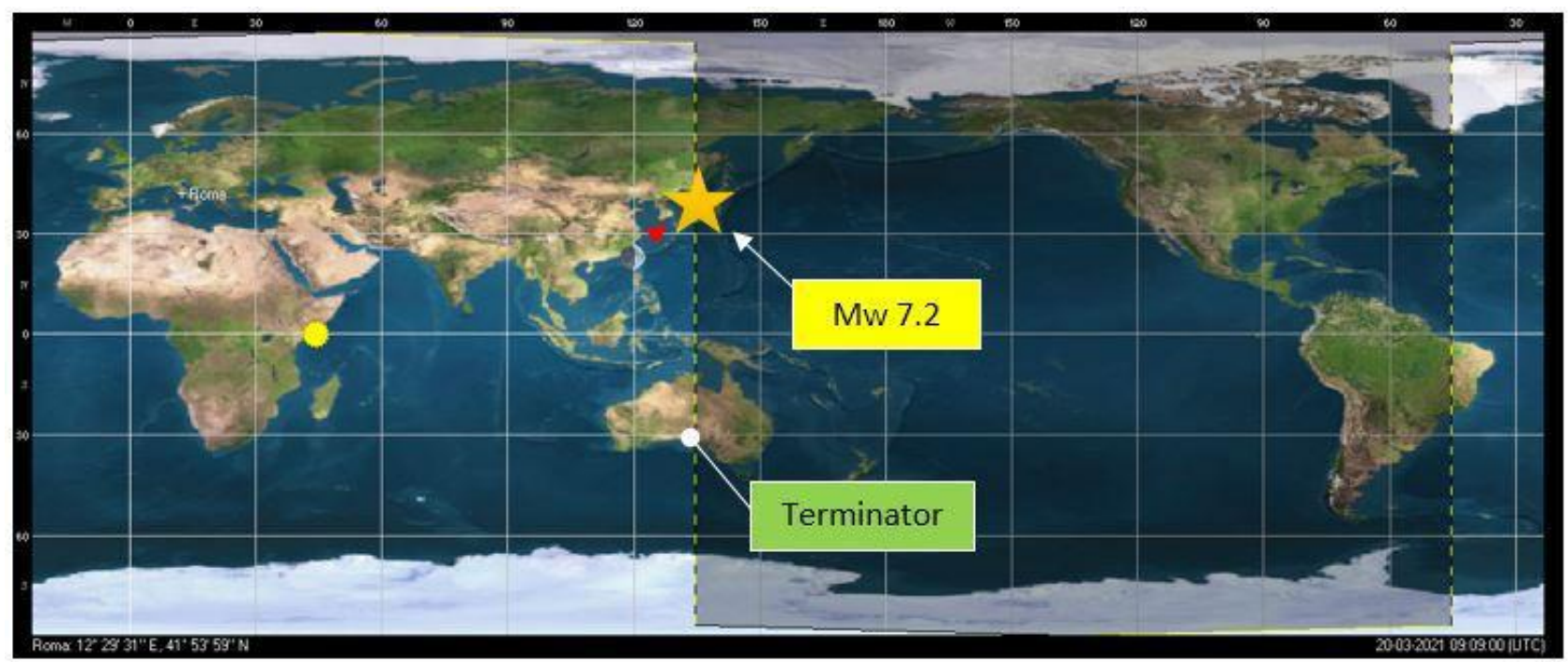

Fig.41 - EarthQuake Mw 7.1 - of 20 March 2021 - $34 \mathrm{~km} \mathrm{E}$ of Ishinomaki, Japan. In this case the earthquake presented itself in close proximity to the terrestrial terminator, and near the lunar zenith. On the map, the time is displayed in Italian local hour, not in UTC but in LT. Credits: Radio Emissions Project, USGS.

\section{3 - DAta AnAlysis}

The study carried out by the group of researchers, began with the analysis of the strong earthquakes to Japan, on 11 March 2011, including that of magnitude $\mathrm{Mw}$ 9.0, the strongest earthquake recorded in the modern era, up to 30 May 2015 and also going to consider the strong earthquakes occurred in March, 2021.

Analyzing these seismic events, it was possible to see how almost all the strong earthquakes took place in the presence of a precise position of the stars and in particular the sun and the Moon. The proximity for example, of strong intensity earthquakes to the terrestrial terminator and the presence, on the zenith of the seismic epicenter, of the Moon, provides us with an undevelopable indication, in relation to the forces acting on the seismic unwear on a global scale.

According to what is formulated by Isaac Newton, through the "Universal Gravitation Law", we know that there is interaction between the celestial bodies. This law also establishes that any body in the universe, understood as a material point, attracts any other body with a force directly proportional to the product of the masses and inversely proportional to the square of the distances [9].
The "gravitational force" is one of the four types of "fundamental forces", also called "fundamental interactions", which is generated by the mass of the bodies. If we analyze this type of strength, we know that it is directed along the right that connects the two bodies and acting so as to approach them. We also know that this force is always applied to the center of mass of the body, so it is presumable to think that the action of "stretching" of the earth's surface that goes to form along the terrestrial terminator, depends on the crushing of the planetary body at the level of the poles, For the effect of attraction. Deforming the spherical of the planet Earth, these forces tend to change the balance of the lithosphere and since the earth turns on its own axis, such forces affect pulse on areas to other tectonic stress [10] [11] [12] [13].

The proximity of the Moon, according to the researchers, is certainly not underestimated, as are the influences between the terrestrial crust and the forces involved that seem to interact, going for example not only to act on the terrestrial terminator, providing with a gravitational traction parallel to the terrestrial surface, but also a certain degree of lifting of the lithosphere, due to the presence of the Moon at Zenit near the seismic epicenter. These forces, combined with the energy 
accumulated in the fault, have certainly influenced the triggering of the strong earthquake in Japan (Fig. 3, 4, 5). These forces are therefore not underestimated in an astronomical context in which these mechanisms are expressed.

The data certainly indicate how there is a net relationship between the position of the stars with respect to the earth's surface (Zenit and the Zenithal Antipodal Point), with highly destructive seismic events. This evidence is visible fromFig. 4toFig. 41, in reference precisely to the gravitational forces that affect the planetary body (scheme 2) [14] [15] [16].

The data indicate how there are forces capable of providing a push to the seismic strip, or to the energy already accumulated on the fault surfaces. It is not a case, in fact, according to the researchers engaged in this study, that the position of the Sun and the Moon are in a "strategic" position with respect to the seismic epicenter. The position of the

\section{4 - ConCLusions}

The conclusions, to which the researchers came is that there is a direct relationship between the "gravitational push" of the Sun and the Moon, and the occurrence of very intense seismic events. This report was highlighted considering the most destructive earthquakes between 2011 and 2015 and going to consider even those that occurred in 2021, to demonstrate how this phenomenon observed and considered (Crustal Relaxing) is actually a phenomenon generated by mechanisms that are repeated Constantly.

In this context of research, however, it is necessary to carry out further study studies to accurately understand how these forces act at the level of the lithosphere or terrestrial cloak. However, it has been highlighted that the interaction of these triggers can only be gravitational, or mediated by

\section{REFERENCES}

[1] http://www.ingv.it/it/stampa-eurp/stampa/comun-icati-stampa/4563-le-mareesolide-muovono-i-continenti-the-earth-s-tidesmove-the-continents.

[2]https://www.ltpaobserverproject.com/archiviora-dioanomalie-2011-precursori-sismici-geomagnetici.html.

[3] www.stoff.pl.

[4]

http://sos.noaa.gov/datasets/Land/day_night.html.
Sun and the Moon determines a different gravitational interaction depending on the position of such stars and celestial bodies [17] [18]. If these stars are, for example, everyone turns into the same geographical area (which from the latter are visible), the interaction is strong, as strong seems to be when the position of the Sun and the Moon are found in opposition. In this case the terrestrial crust and the fluid body of the Earth are pushed into different directions, as it happens by pulling an elastic.It is obvious that at the crusta level this traction/movement affects the measures and distances that are characteristic of the litigation structures present at the level of the fault. A sliding or shift and the earthquake is triggered on these structures.

A phenomenon, that of "Crustal Relaxing", which therefore seems determined by the gravitational interaction and that tends to provide a "push" to the faults in which energy has accumulated.

the strength of attraction of the masses of the celestial bodies and the Sun, involved in the seismogenetic mechanism. The energy accumulated at the level of the faults, acts as a "charge", whose energy release is then facilitated/activated in part even by the gravitational interaction. It is obvious that when more extensive is the fault and the greater the energy in accumulation, and stronger and vigorous is this gravitational interaction. There is no doubt, therefore, that the gravitational interaction of the celestial bodies must be a phenomenon to be considered in the scientific area, in a context of seismic prediction. The distension of the terrestrial crust associated with the gravitational interaction is according to the researchers, a new phenomenon of seismic trigger to be considered in the future, in the field of earthly seismogenetics.

[5] David Harry Grinspoon, Venus Revealed, Perseus Books Group, 1998, p. 329, ISBN 978-0201-32839-4.

[6]

https://online.scuola.zanichelli.it/lupiaterra2ed/files /2009/03/terra_sintesi3.pdf.

[7]

https://writescience.wordpress.com/2014/08/25/stand-in-the-shadow-of-the-moon/. 
[8] L'Interno della Terra - Carlo Doglioni -2007. http://www.dst.uniroma1.it/sites/default/files/-

doglioni/2007InternoTerraTreccani.pdf

[9] Legge di Gravitazione Universale - Isaac Newton.

[10]

https://people.unica.it/alessiofilippetti/files/2019/10

/Forza-Gravitazionale.pdf

[11] Roger Penrose, La strada che porta alla realtà. Leggi e fondamenti dell'universo, Milano, BUR, 2015, p. 440.

[12] Roger Penrose, La strada che porta alla realtà. Leggi e fondamenti dell'universo, Milano, BUR, 2015, p. 441.

[13] Roger Penrose, La strada che porta alla realtà. Leggi e fondamenti dell'universo, Milano, BUR, 2015, pp. 441-442.

[14] Feynman, Richard P. (1967). The Character of Physical Law. MIT Press. ISBN 0-262-56003-8.

[15] Weinberg, S. (1993). The First Three Minutes: A Modern View of the Origin of the Universe. Basic Books. ISBN 0-465-02437-8.

[16] Weinberg, S. (1994). Dreams of a Final Theory. Vintage Books USA. ISBN 0-679-744088.

[17] Padmanabhan, T. (1998). After The First Three Minutes: The Story of Our Universe. Cambridge University Press. ISBN 0-521-62972-1.

[18] Perkins, Donald H. (2000). Introduction to High Energy Physics. Cambridge University Press. ISBN 0-521-62196-8.

[19] Manuale del geologo - Il $1^{\circ}$ manuale del geologo online in Italia https://manualedelgeologo.it/astenosfera. 